C)2021. Licensed under the Creative Commons Attribution-NonCommercial-NoDerivatives 4.0 International http://creativecommons.org/about/downloads

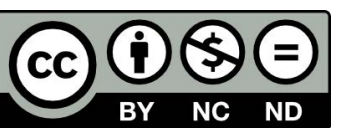

This is the accepted version of this paper. The version of record is available at https://doi.org/10.1016/ j.compbiomed.2021.104303 


\title{
Biomechanical evaluation of glass fiber/polypropylene composite bone fracture fixation plates: Experimental and numerical analysis
}

\author{
Ali Kabiri a , Gholamhossein Liaghat ${ }^{a}$, ,* $^{*}$ Fatemeh Alavi ${ }^{a}$ \\ ${ }^{a}$ Faculty of Mechanical Engineering, Tarbiat Modares University, Tehran, Iran \\ ${ }^{\mathbf{b}}$ School of Mechanical \& Aerospace Engineering, Kingston University, London, UK
}

\begin{abstract}
Little is known about the impact behavior of composite fixation plate used in the fracture healing of long bones diaphysis. Hence, this study examined polypropylene composite fixation plates using different glass fibers and measured their biomechanical responses under axial impact loading experimentally and numerically. Short randomly oriented, long unidirectional prepregs and fiber yarn of glass were considered as reinforcements, and fixation plates were fabricated through two different heat-compressing and 3D printing processes. Furthermore, assessing the fixation plate structures impact behavior was carried out using in vitro impact test and finite element analysis (FEA). Impact damping behavior, damage mechanisms, and stress and strain pattern of the composite fixation plate structures were obtained under various bone fractures and impact energies. The impact load-time responses and the failure mechanisms demonstrated that fixation plate structures with more plastic behavior and lower stiffness could act as an initial shock absorber and dampen the transmission of axial impact load by distributing the impact energy over time. Therefore, considering the ability of stress shielding and adequate
\end{abstract}

*Corresponding author.

Gholamhossein Liaghat, Tarbiat Modares University, Jalal-e-Al-Ahmad, Tehran 14115111, Iran.

Email: ghlia530@modares.ac.ir, g.liaghat@kingston.ac.uk 
interfragmentary movement which amplifies bone ossification, the proposed Glass Fiber/PP (GF/PP) composite fixation plates could serve as a proper alternative in orthopedics.

Keywords: Fixation plate, Glass Fiber/PP composites, 3D printing, Impact behavior, In vitro biomechanical test, Finite element analysis.

\section{Introduction}

Rigid stainless steel or titanium alloy fixations were introduced more than 100 years ago. Although some of their shortcomings, such as corrosion and wear, have been eliminated [1], other major issues, like hardware failure, plate pull-off, and delayed union, were more persistently problematic. Recently, fixations with fracture healing accelerating abilities have been developed. The most critical problem is the mismatch of the metallic fixation plate and the human bone elastic moduli, which leads to the stress-shielding effect. This effect prevents the generation and development of healed bone at the fracture site and may cause some severe osteoporosis and bone re-fracturing problems during the healing period. Furthermore, it has been widely accepted that both insufficient and extra fracture movement, which is due to the stiffness of the fracture fixation structure, can prevent the formation of callus in the fracture zone [1]. Decreasing the fixation plate rigidity produces a more reasonable load sharing between the plate and the bone, while good primary fixation is still kept. A low-stiffness plate also allows some micro-motion at the fracture zone, helping callus formation and better bone healing.

Due to the high strength to weight ratio, biomechanical compatibility, radiolucency, and low stiffness, composite materials have been introduced to address the drawbacks of metallic fixation plate. These materials show linear elastic behavior under normal daily activities and have a high energy absorption capability. In addition, it has been reported that polymeric composite materials have higher fatigue resistance than stainless steel, which provides 
sustainable cyclic loading during daily activities [2]. Random short and long fibers, unidirectional fiber laminates, and textile fabric laminates are different reinforcements for polymer-based fiber composites. Fiber-reinforced composites have many advantages because of their material properties, and their noncorrosive nature. Different types of fibers, including carbon fiber (CF), glass fiber (GF), silk, and flax, have been widely used to fabricate the composite implant in thermoset and thermoplastic matrices, including epoxy, polylactic acid (PLA), poly-L-lactic acid (PLLA), and lactic acid-co-glycolic acid (PLGA) [2]. By changing the fibers volume fraction and arrangements, the composite implants mechanical properties could more closely resemble the human bone.

The fixation plates are usually designed to tolerate different loading conditions in daily activities, such as standing, walking, running, and climbing stairs; however, incidents involving falls or traffic accidents are not uncommon. Therefore, the load conditions should include impact loadings as well. Various phenomena such as stress waves transfer and impact damping resistance could occur in structures during impact loading because of the physical and mechanical properties of the materials, structural geometry, speed, angle of impact loading, and complexity of the structures impact behavior.

Due to the difficulties of performing in vitro/in vivo biomechanical tests, most studies on composite fixation plates have been carried out numerically [3-5]. However, a few studies have conducted impact loading analysis on the conventional metallic plates. Coates et al. [6] conducted three-point impact bending tests on cadaveric ulnas with and without mid-shaft dynamic compression plates using the finite element (FE) method to predict bone damage. Capanni et al. [7] compared axial impact damping of three types of fixation methods, including standard locking plate system, dynamic locking plate system, and Ilizarov ring fixator under drop incident. Their results indicated that the dynamic locking plate decreased the maximum force applied to the bone during impact loading and also decreased the structural stiffness. 
It seems that no study has investigated the experimental-numerical analysis of impact loading on the composite fixation plate structure (i.e., the assembly of the fixation plate to the bone with screws). Hence, this study evaluated the biomechanical performance of newly internal fracture fixation plates made of glass fiber reinforced polypropylene (Glass Fiber/PP), which have enough strength and low elastic modulus to replace with traditional metallic plates. Additionally, three-dimensional finite element models have been analyzed using ANSYS software, and the accuracy of the FE models was validated with experimental tests. The main goal of this research is to analyze biomechanical parameters such as impact damping behavior (transmitted peak force to the fixation plate structures and impact duration), stress and strain of the fixation plates, and damage mechanisms of them in the various types of bone fractures and impact energies.

\section{Materials and experimental methods}

\subsection{Composite fixation plates preparation}

Due to the possible toxicity and the lack of reshaping ability during surgery, thermoset composites are not proper choices to be used in internal fixation devices [2]. Furthermore, at room temperature $\left(30^{\circ} \mathrm{C}\right)$, the water content in the polypropylene and the degradation rate of the bending stiffness and flexural strength are very low, and also the glass fibers can reduce the water absorption rate [8]. Also, GF/PP composites are biocompatible [2]. Thus, it can be concluded that the GF/PP composites are good candidates for a long-term orthopedic implant in the human body. Hence, to investigate the most appropriate mechanical properties, reinforced polypropylene using PP/Short Chopped Glass Fiber (PPSCGF), PP/Long Glass Fiber (PPLGF), and PP/Long Glass Fiber Yarn (PPLGFY) were fabricated in this study.

It has been reported that the location of the screws near the fracture site plays a significant role in the fixation plate structure stiffness. It is also suggested that at least three screws should be 
used on each side of the bone fragment [9]. Hence, the standard model for the tibia mid-shaft fixation plate was generated at $110 \mathrm{~mm}$ length, $25 \mathrm{~mm}$ width, and $5.5 \mathrm{~mm}$ thickness with six screws (Figure 1-a).

The PPSCGF granules with a density of $1.04 \mathrm{~g} / \mathrm{cm}^{3}$ and a volume fraction of $15 \%$, and 20 prepregs layers of unidirectional fiber orientation of the PPLGF with a density of $1.27 \mathrm{~g} / \mathrm{cm}^{3}$ and a volume fraction of $30 \%$ were used to manufacture two types of fixation plates. The stainless-steel mold die with six pins was put into a hot-press machine and it was heated to $230^{\circ} \mathrm{C}$ for $10 \mathrm{~min}$ to avoid relaxation of the reinforcing polymer fibers. During compression molding, the materials were kept at a constant pressure of $3 \mathrm{MPa}$ for $20 \mathrm{~min}$ and then slowly cooled in the mold in order to allow high crystallinity to form in the matrix structure (Figure 1-b) [10]. When the mold temperature reached $40^{\circ} \mathrm{C}$, the composite fixation plate was removed from the press.

The usage of three-dimensional (3D) printing technique for bone implants production rapidly grows in tissue engineering $[11,12]$. Hence, the PPLGFY composite fixation plate was fabricated using this technique in the present study. The opportunity to implement advanced manufacturing methods (additive manufacturing technique) to produce the composite fixation plate with higher fiber and matrix bonding strength was investigated. In-melt continuous glass fiber yarn embedding was applied as a reliable and consistent method for simultaneous impregnation to produce continuous fiber-reinforced thermoplastic composites in the fused deposition modeling process [13]. The plate model was prepared as a G-code file using slic3r V1.3.0 software for 3D printing. The PP filament with a diameter of $1.75 \mathrm{~mm}$ was initially placed in a heating jacket to heat up $220^{\circ} \mathrm{C}$, then extruded through the nozzle with an inner diameter of $0.4 \mathrm{~mm}[10]$. As illustrated in figure 1-c, the input E-glass fiber yarn was held by a pulley, and then it was released into the nozzle and embedded into a molten area. The nozzle and the bed temperatures were set at $220^{\circ} \mathrm{C}$ and $80^{\circ} \mathrm{C}$, respectively. The thickness of each 
constructed layer was $0.22 \mathrm{~mm}$. To ensure smooth printing, the print speed was configured at $5 \mathrm{~mm} / \mathrm{sec}$. E-glass fiber yarn was used with a mass per length of about $0.1 \mathrm{~g} / \mathrm{m}, 15 \%$ volume fraction, and its nominal strength was $1000 \mathrm{MPa}$.

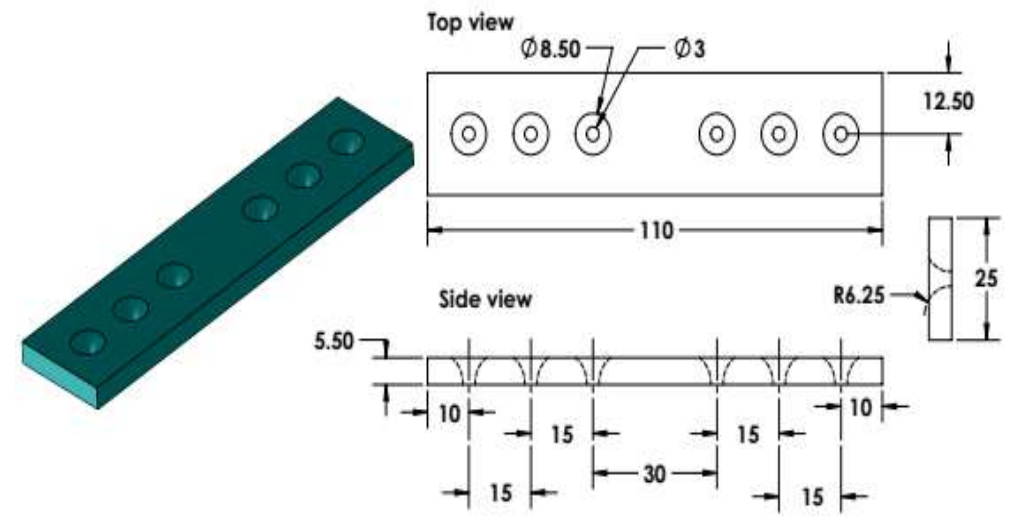

(a)
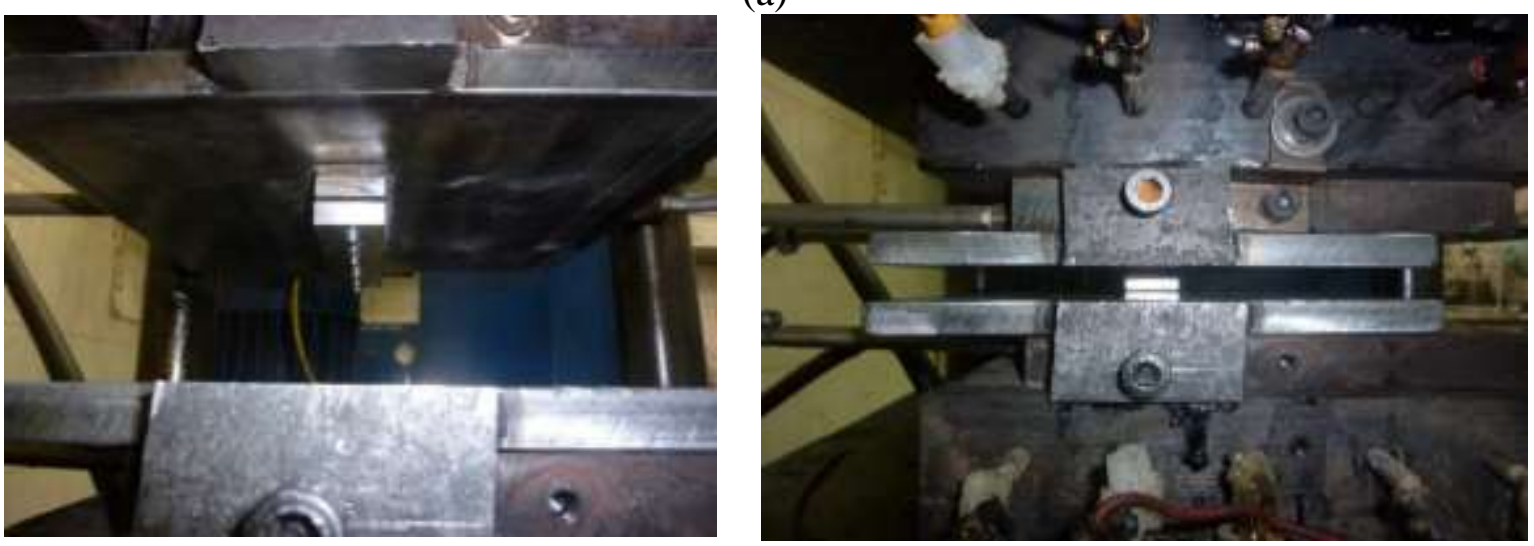

(b)
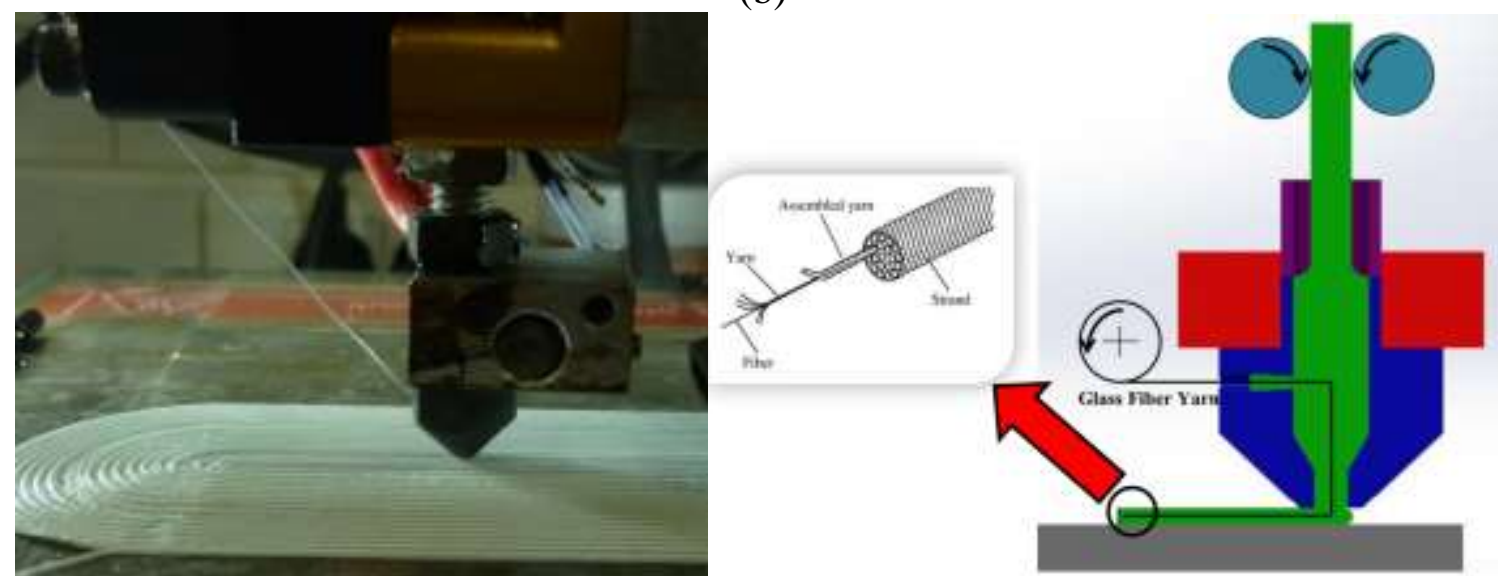

(c)

Figure 1. (a) Specimen geometry of the composite fixation plate (All dimensions in $\mathrm{mm}$ ). (b) Manufacturing specimens by thermoforming hot press method [10]. (c) 3D printing technique manufacturing [10].

The sharp edges were removed after the completion of the production process in both methods.

The fabricated composite fixation plates are shown in figure 2. 


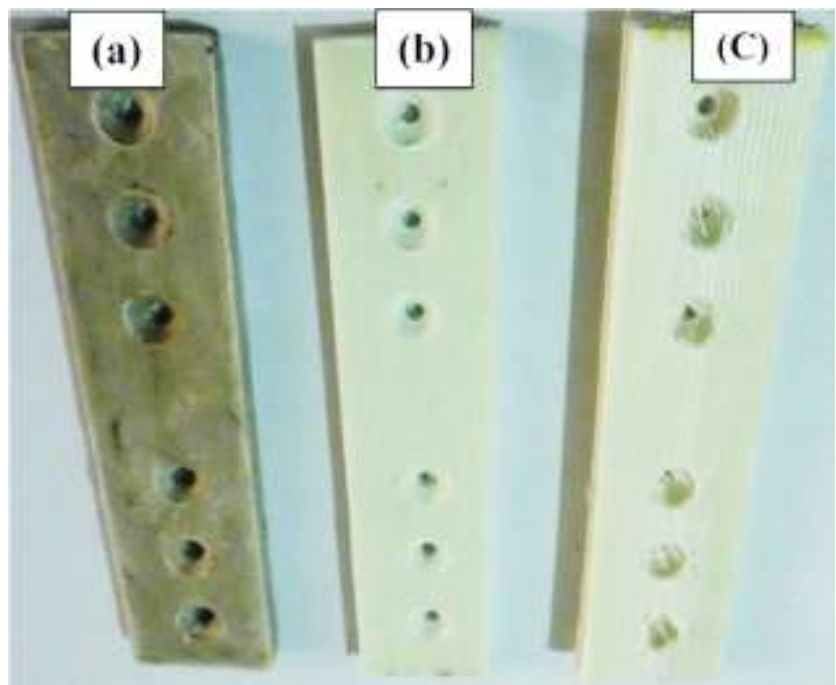

Figure 2. Fabricated composite fixation plates, (a) PPSCGF, (b) PPLGF, and (c) PPLGFY [10].

\subsection{Mechanical characterization}

Mechanical property tests including density (ASTM D792), tensile (ASTM D3039), compression (ISO844), four-point bending (ASTM D7264), shear (ASTM D3518), and Charpy impact resistance (ASTM D6110) were performed at room temperature on all three GF/PP composite specimens, and the required parameters of the numerical simulations were extracted from the results of the tests [10]. To evaluate the effect of glass fibers on the properties of these composites, neat PP samples were also made for comparison tests.

To obtain an accurate strain field, the digital image correlation (DIC) technique has been used in the tensile, compression, and shear tests [10].

The obtained mechanical properties and manufacturing process parameters of each specimen are shown in table 1. In order to investigate the reliability of the results, each test was replicated with six samples and the mean values and the standard deviations (SD) were calculated. Table 1 illustrates various mechanical properties including density $(\rho)$, Young's modulus $\left(E_{1}, E_{2}, E_{3}\right)$, tensile $\left(\sigma_{U 1}^{T}, \sigma_{U 2}^{T}, \sigma_{U 3}^{T}\right)$ and compressive $\left(\sigma_{U 1}^{C}, \sigma_{U 2}^{C}, \sigma_{U 3}^{C}\right)$ strength, shear modulus $\left(G_{12}, G_{13}, G_{23}\right)$ and strength $\left(\tau_{12}, \tau_{13}, \tau_{23}\right)$, Poisson's ratio $\left(v_{12}, v_{13}, v_{23}\right)$, flexural modulus $\left(E_{B}\right)$, strength $\left(\sigma_{U}^{B}\right)$, and impact resistance (IR) of the tested samples. 
Table 1.Manufacturing methods and obtained values of mechanical properties $(1,2$, and 3 are the principal directions) [10].

\begin{tabular}{|c|c|c|c|c|}
\hline Specimen & PPSCGF & PPLGF & PPLGFY & Neat PP \\
\hline $\begin{array}{c}\text { Manufacturing } \\
\text { method }\end{array}$ & Hot-press & Hot-press & 3D print & Hot-press \\
\hline$\rho\left(k g / m^{3}\right)$ & $1040 \pm 10$ & $1270 \pm 10$ & $490 \pm 10$ & $946 \pm 5$ \\
\hline$E_{1}(G P a)$ & \multirow{3}{*}{$2.35 \pm 0.15$} & $20.10 \pm 2$ & $7.87 \pm 0.5$ & \multirow{3}{*}{$0.77 \pm 0.1$} \\
\hline$E_{2}(G P a)$ & & $4.20 \pm 0.3$ & $1.00 \pm 0.2$ & \\
\hline$E_{3}(G P a)$ & & $4.20 \pm 0.3$ & $1.00 \pm 0.2$ & \\
\hline$\sigma_{U 1}^{T}(M P a)$ & \multirow{3}{*}{$30 \pm 5$} & $400 \pm 30$ & $150 \pm 20$ & \multirow{3}{*}{$20 \pm 5$} \\
\hline$\sigma_{U 2}^{T}(M P a)$ & & $20 \pm 2$ & $10 \pm 1$ & \\
\hline$\overline{\sigma_{U 3}^{T}(M P a)}$ & & $20 \pm 2$ & $10 \pm 1$ & \\
\hline$\sigma_{U 1}^{C}(M P a)$ & \multirow{3}{*}{$45 \pm 5$} & $70 \pm 5$ & $20 \pm 5$ & \multirow{3}{*}{$30 \pm 5$} \\
\hline$\sigma_{U 2}^{C}(M P a)$ & & $50 \pm 5$ & $15 \pm 5$ & \\
\hline$\sigma_{U 3}^{C}(M P a)$ & & $50 \pm 5$ & $15 \pm 5$ & \\
\hline$G_{12}(G P a)$ & \multirow{3}{*}{$0.8 \pm 0.1$} & $1.42 \pm 0.2$ & $1.15 \pm 0.2$ & \multirow{3}{*}{$0.35 \pm 0.1$} \\
\hline$G_{13}(G P a)$ & & $1.33 \pm 0.2$ & $1.1 \pm 0.2$ & \\
\hline$G_{23}(G P a)$ & & $1.33 \pm 0.2$ & $1.1 \pm 0.2$ & \\
\hline$\tau_{12}(M P a)$ & \multirow{3}{*}{$20 \pm 5$} & $40 \pm 2$ & $20 \pm 2$ & \multirow{3}{*}{$10 \pm 5$} \\
\hline$\tau_{13}(M P a)$ & & $30 \pm 2$ & $10 \pm 2$ & \\
\hline$\tau_{23}(M P a)$ & & $30 \pm 2$ & $10 \pm 2$ & \\
\hline$v_{12}$ & \multirow{3}{*}{$0.35 \pm 0.05$} & $0.15 \pm 0.05$ & $0.25 \pm 0.05$ & \multirow{3}{*}{$0.45 \pm 0.05$} \\
\hline$v_{13}$ & & $0.10 \pm 0.05$ & $0.15 \pm 0.05$ & \\
\hline$v_{23}$ & & $0.10 \pm 0.05$ & $0.15 \pm 0.05$ & \\
\hline$E_{B}(G P a)$ & $2.1 \pm 0.2$ & $16.2 \pm 0.2$ & $2.3 \pm 0.2$ & $0.9 \pm 0.2$ \\
\hline$\sigma_{U}^{B}(M P a)$ & $27 \pm 5$ & $185 \pm 5$ & $44 \pm 5$ & $35 \pm 5$ \\
\hline$I R\left(k J / m^{2}\right)$ & $22 \pm 5$ & $162 \pm 5$ & $68 \pm 5$ & - \\
\hline
\end{tabular}

The written values are the mean value and the standard deviation (SD) of the obtained measurements from the properties tests.

\subsection{In vitro experimental procedure}

Due to the similarities between bovine and human tibia with respect to their geometries and mechanical properties [14], the bovine tibia was used in this research. The fresh bovine tibia bones immediately after slaughter were thawed, and the surrounding soft tissues were removed. They were kept according to the corresponding protocols [14]. 
Due to orthopedic technical drawbacks, such as plate over bending and the fracture configuration, variable amounts of the gap at the fracture site happen. To prepare fractured bone specimens, the specimens were cut in half with a saw. The fixation plate structures were placed in $1 \mathrm{~mm}$ (stable fracture) and $10 \mathrm{~mm}$ (unstable fracture) gap to simulate the stable and unstable fracture types. Then, the bones were drilled to accommodate six 3-mm metallic cortical screws. Non-contact fixation plate system (i.e., the fixation plate and screws) using an automatic screwdriver was mounted on both stable and unstable fractures bone according to Ahmad et al. [15] suggestion (Figure 3). Alignment, drilling, and placing the screws were conducted based on the corresponding standards [14]. Finally, the distal end of the fixation plate structure was fully fixed in a designed fixture using PMMA cement, and the pot was fixed in all directions.

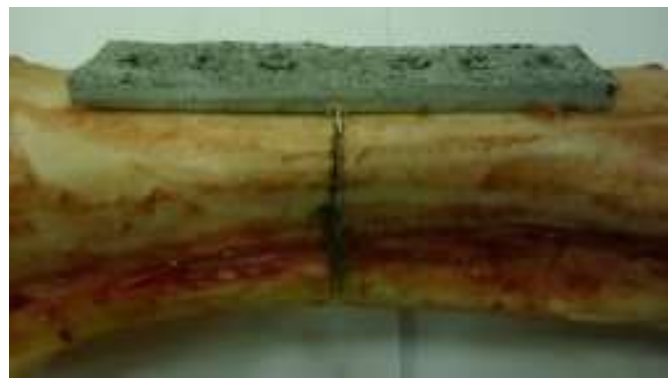

(a)

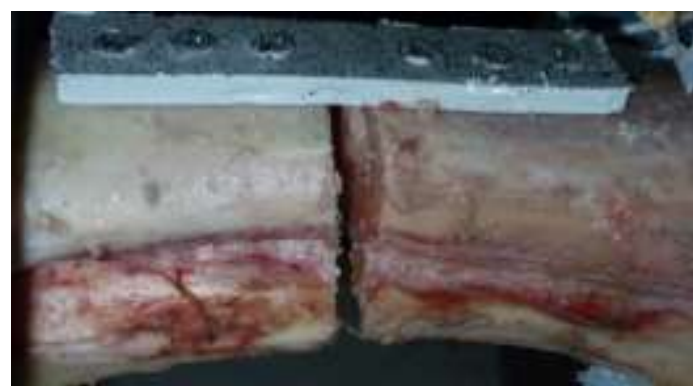

(b)

Figure 3. Types of fractures, (a) stable fracture (1 mm gap), and (b) unstable fracture $(10 \mathrm{~mm}$ gap).

The drop weight apparatus with a $40 \mathrm{~kg}$ striker was employed to accomplish the experimental procedure. The experiment was designed to apply $70 \mathrm{~J}$ energy, which simulates the fall of a 70 $\mathrm{kg}$ person on one foot from $10 \mathrm{~cm}$ height (Figure 4). 


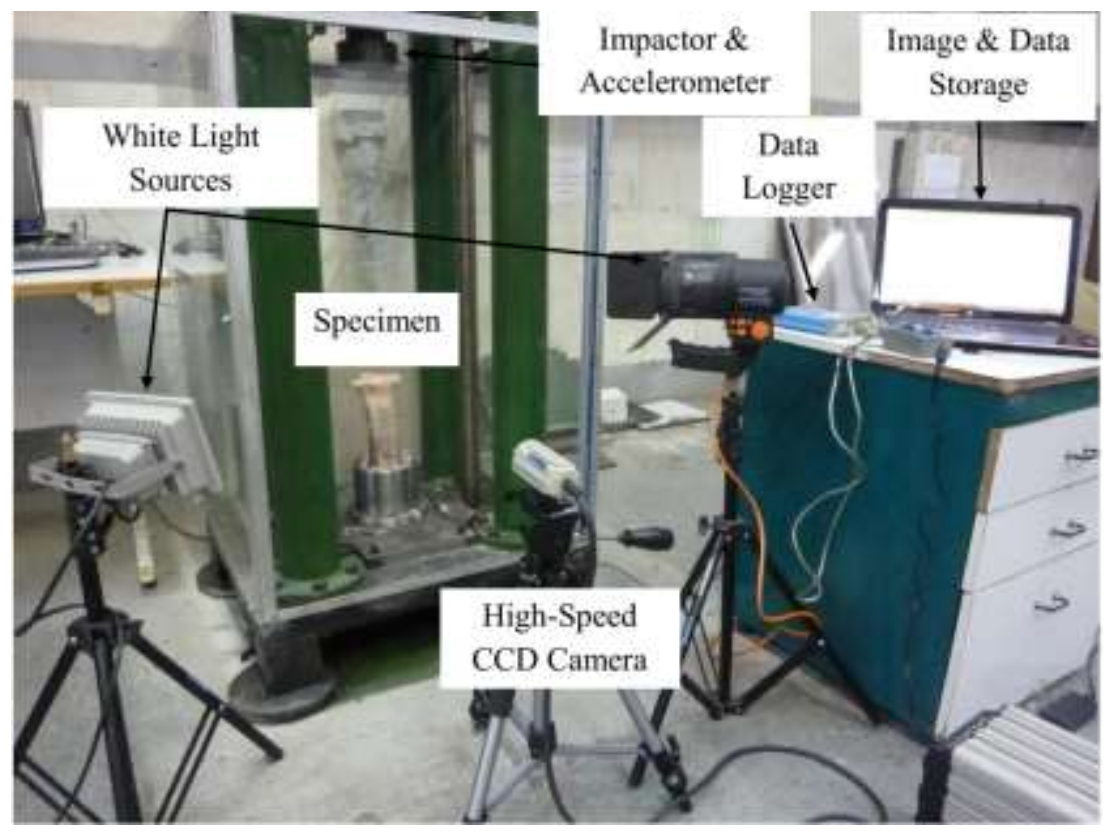

Figure 4. Drop weight test setup.

To assess the deformation and strain field of fixation plate systems, a $2 \mathrm{D}$ digital image correlation system was used. For this purpose, fixation plate systems had been sprayed with speckle pattern according to the standard protocols [16]. A high-speed charge-coupled device (CCD) camera (FASTCAM MH4-10K) with a frame rate of $1000 \mathrm{fps}$ was used in this test. The fixation plates deformation and strain field were calculated using the GOM software (ZEISS Corp., Germany). Moreover, a piezoelectric accelerometer with the ability to record 96,000 data per second was used to record global acceleration during the test. Outputs were filtered using Channel Frequency Class (CFC), and impact load value was obtained directly from the force-time curve calculated by Newton second motion law. Impact damping behavior and fracture load value were obtained directly from the force-time curve. The precision and accuracy of these measurement systems have been reported in various studies [17-19]. Worth noting is that five specimens for each fixation plate structures were tested to obtain reliable results. 


\section{Finite element analysis}

Since 1972 finite element method (FEM) was used in orthopedic biomechanics to evaluate stresses in bones, bone-prosthesis structures, and fracture fixation devices [20]. Moreover, it has been employed to assess new configurations, materials, and shapes of implants without the necessity of using experimental tests. In this study, the finite element software ANSYS Workbench 19.0 (ANSYS Inc., Canonsburg, PA, USA) was used for the explicit analysis. To the best of the author's knowledge, no study has developed a three-dimensional finite element model to evaluate impact loading effects on composite fixation plate structures.

\subsection{Modeling of fixation plate structures}

The three-dimensional bone model was obtained from computed tomography (CT) scans of the bovine tibia. The digital imaging and communications in medicine (DICOM) files were converted to STL files to design bovine tibia using CAD software (SolidWorks, Dassault Systems SolidWorks Corp., Inc., USA). The porosity of bone can be divided into the cortical bone (5-15\% porosity) and the trabecular bone (30-90\%). Bone is an anisotropic material owing to its direction-dependent properties. In the modeling, both cortical and trabecular parts

of the bone were considered (Figure 5). The three-dimensional geometry of the fixation plate system and fracture gap was constructed in SolidWorks software and assembled according to the experimental model. The screws were modeled as 3-mm cortical screws without threads. The transverse distance of $1 \mathrm{~mm}$ and $10 \mathrm{~mm}$ between bone fragments was applied to represent the stable and unstable fractures, respectively (Figures 6-a and 6-b). Finally, the fixation plate structure was imported into the ANSYS Workbench as Parasolid files. In experiments, distal PMMA cement was used to fix the specimen, which was modeled in simulations. 

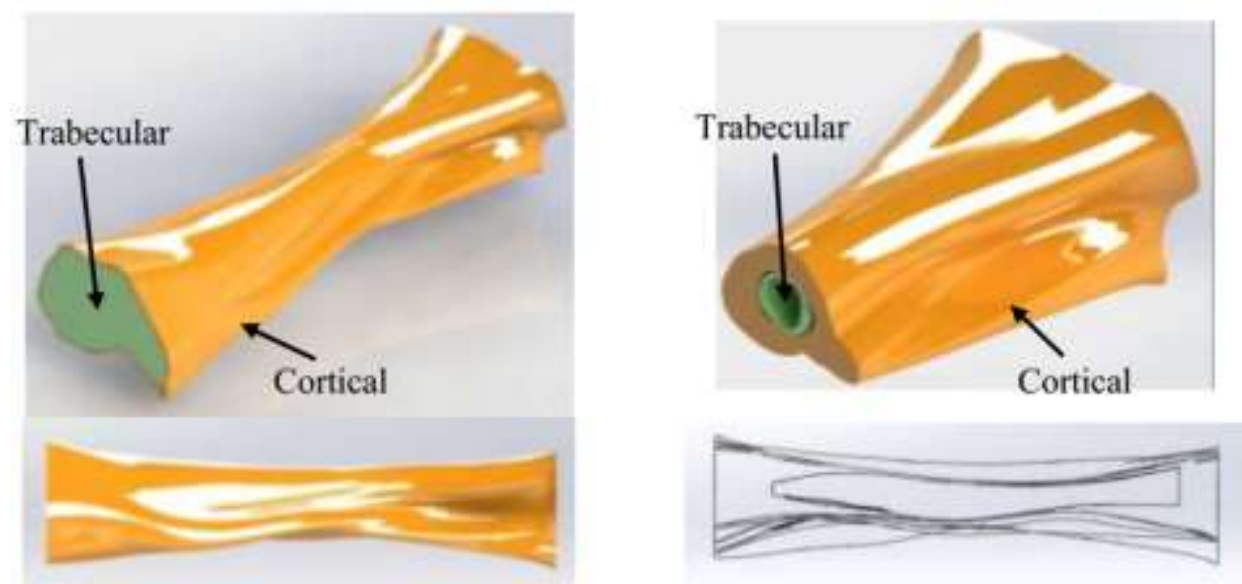

Figure 5. Different views of bovine tibia bone model.

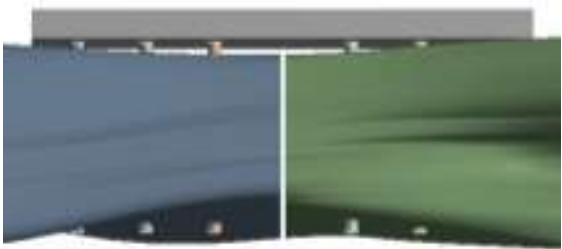

(a)
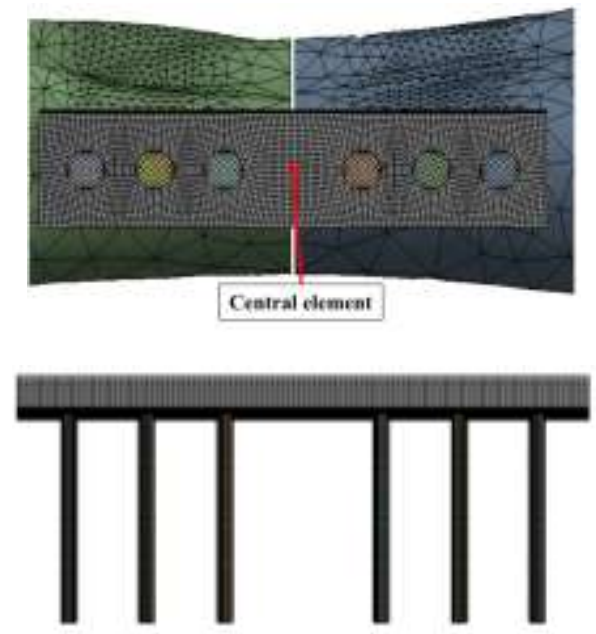

B Fied Suppoit

Goth Oresity $9006.6 \mathrm{~mm} / \mathrm{t}^{2}$

C] Velocity

D. Dok Preteruions 5C N

Bok Pretrersion a s 50. N

Bok Pretenian at $20 . \mathrm{N}$

Hak Protatian te 50.1

Dok Protamian $5: 50 . \mathrm{N}$

Bok Preteniien $650 . N$

(c)

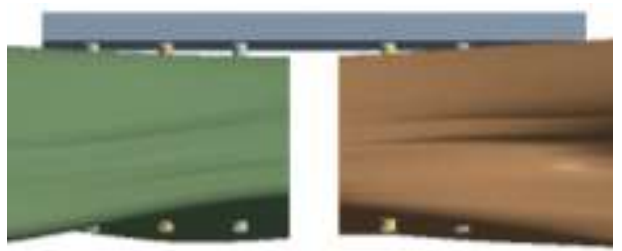

(b)

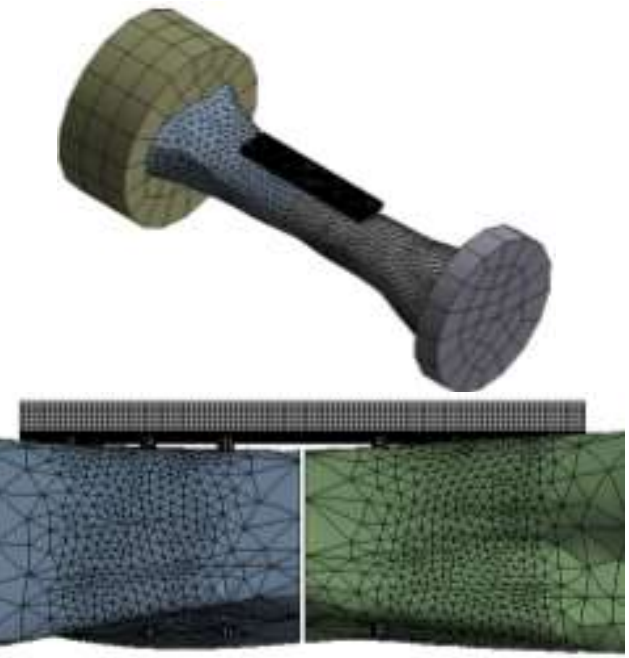

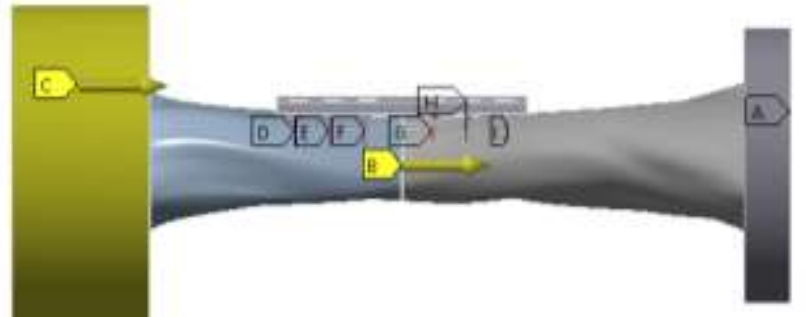

(d)

Figure 6. (a) Stable, (b) unstable bone fracture, (c) mesh generation of the fixation plate structure, and (d) applied impact loading and boundary conditions in finite element analysis. 


\subsection{Material properties assignment and damage theory}

Due to the strain rate effect, the material properties are slightly different in the impact loading. The effect of strain rate on the GF/PP and neat PP mechanical properties at different fiber percentages and angles was obtained by Schoßig et al. [21]. They found that the mechanical properties of GF/PP and neat PP increase 1.5 times in a high strain rate. Hence, the update values according to the reported ones in table 1 were used in the finite element simulation. There is no method to determine the criterion for element removal; thus, the required parameters must be determined by trial and error in comparison with laboratory results [22]. Many algorithms have been suggested for damage prediction of structures in high strain rate loading conditions in recent years [22]. As for combined loading, including tension, compression, and bending was influential in the model, the use of maximum principal stress theory is suitable for predicting damage mechanism and the load capacity of the fixation plate system [22]. In this theory, the stress amplitude increases until damage initiated in one of the elements according to the failure criterion. The element will immediately be removed whenever the material response of each element exceeds the defined value.

The major challenge was the implementation of the realistic bovine tibia bone material behavior in the computational models. Various studies [23, 24] used Hopkinson test at different strain rates to obtain different parts of bovine tibia bone properties. According to their results, increasing the strain rate results in about $20 \%$ and $40 \%$ rise in bovine tibia elastic modulus and strength, respectively. The applied mechanical properties of trabecular and cortical bovine tibia bone are summarized in table 2 . 
Table 2. Mechanical properties of bovine tibia [23, 24] $(1,2$ and 3 are the principal directions).

\begin{tabular}{|c|c|c|}
\hline Properties & Cortical & Trabecular \\
\hline$\rho\left(k g / \mathrm{m}^{3}\right)$ & 2000 & 1100 \\
\hline$E_{1}(G P a)$ & 25.7 & \multirow{2}{*}{2.1} \\
\hline$E_{2}(G P a)$ & 20.4 & \\
\hline$E_{3}(G P a)$ & 18.1 & \multirow{2}{*}{0.8} \\
\hline$G_{12}(G P a)$ & 3.7 & \\
\hline$G_{13}(G P a)$ & 2.8 & \multirow{2}{*}{0.25} \\
\hline$G_{23}(G P a)$ & 2.8 & \\
\hline$v_{12}$ & 0.25 & \\
\hline$v_{13}$ & 0.17 & \\
\hline$v_{23}$ & 0.17 & \\
\hline
\end{tabular}

In the modeling procedure, $316 \mathrm{~L}$ medical grade stainless steel screws were considered linear isotropic elastic with elastic modulus and Poisson's ratio of $191 \mathrm{GPa}$ and 0.3 , respectively [3].

\subsection{Meshing and interface conditions}

The finite element mesh generation module of ANSYS Workbench was used to create a mesh of areas and volumes. Bone and PMMA cement were meshed using SOLID72 elements, and the fixation plate system (plate and screws) were meshed by quadratic SOLID95 elements from the ANSYS Workbench element library (Figure 6-c). These solid elements have a translation in the $\mathrm{x}, \mathrm{y}$, and $\mathrm{z}$ directions, and they can also be assigned anisotropic material properties. Preliminary model solutions were used to identify areas with high discretization errors. It was apparent that the most critical area for mesh refinement was in the region surrounding the screw holes. Approximately 125,000 elements with refinement around screw holes were used in the model. Using fine meshes around the screw holes cause adequate stress transfer between plate and screws and more accurate results.

A bonded connection was used at the trabecular interface to cortical bone, cement to the bone, and screws head to plate. Direct contact between the bone and plate was not needed based on 
the experimental model, but non-linear frictional sliding contacts were applied at the screwsbone interface to simulate a more realistic interfacial condition. Since modeling the interaction between the bone and screw is challenging, it was tackled differently in various studies. For the friction coefficient, a standard Coulomb friction coefficient of 0.4 was employed based on some recent studies for the non-locking screw system [3, 4]. All contacts were modeled using surface-to-surface contact elements with penalty contact behavior.

\subsection{Boundary conditions and applying impact loading}

A rigid impactor with $70 \mathrm{~kg}$ weight was dropped to the top layer of the upper bone segment. Falling heights were set 5, 10, and $20 \mathrm{~cm}$ to simulate the different falling energies for human with $70 \mathrm{~kg}$ weight. In order to reduce the runtime, the initial velocities $(1,1.41$, and $2 \mathrm{~m} / \mathrm{s})$ were applied in the x-direction, and the impactor was fully constrained except in the direction along which the velocity was defined (It was constrained in the $\mathrm{y}$ and $\mathrm{z}$ directions). Fixed support ( $u x, u y, u z=0$ ) condition was applied to the lower rigid fixture block. Based on the effect of screw tightening [25], the screw tensile pre-load of $50 \mathrm{~N}$ was applied to the interface of bone with six orthopedic screws (Figure 6-d). Finally, the hourglass control (under axial loading, the hourglass energy was found to be within 5\% of internal energy) and element deletion options were activated. The damage criterion was chosen to automatically decrease the mechanical properties of elements as a function of damage intensity during the impact loading. Mass scaling was not applied, but by setting the maximum time step to $1000,5.5 \times$ $10^{-12} \mathrm{sec}$, stable time increment was achieved in simulations.

It should be noted that different factors, such as the effect of muscle forces and knee joint movement, which could potentially lead to increase bone fixation load-bearing and decrease plate stress, were not considered in this study. It can also be said; the FEA method can be 
refined and applied to a model based on human CT data in the future. This will permit the FE model to be used to simulate realistic loading under clinical conditions.

\subsection{Convergence test and model verification}

The convergence test was conducted to verify the numerical model and illustrate that no further mesh refinement was required. The strain energy and maximum equivalent Von-Mises stress values of the fixation plate were investigated for convergence. Convergence was achieved by increasing the number of elements from 50,000 to 200,000 in five steps. Both the strain energy and the equivalent maximum Von-Mises stress show convergence to $2 \%$ at 125,000 elements. Also, the elements quality was close to 1 , while aspect and Jacobian ratios of the elements were from 0 to 20 and 0 to 1 , respectively. To prevent low-quality solution, the aspect ratio values greater than 10 should not be used [26], which was well respected in our numerical model. The Jacobian ratio criterion should be greater than 0.25; however, a few elements (less than 5\%) had less Jacobian ratio value than that in this study. According to all of the mentioned criteria, acceptable quality can be considered for the selected elements in this analysis.

\section{Validation}

The computational models need to be validated by in vitro/in vivo experimental tests. Therefore, a comparison of the experimental and numerical impact load-time curves of all fixation plate structures for $70 \mathrm{~J}$ impact energy in the stable and unstable bone fractures are shown in figure 7 . The computational models overestimated the stiffness of the experimental models. This could be due to some factors, such as over-estimation of material or interaction properties. The discrepancy between the numerical results and the experimental data can also be attributed to the simplified modeling of the FE analysis cortical/trabecular bone interface. Force values obtained from the model exceeded the experimental ones in the fracture test, which is unsurprising due to its inability to represent the energy lost due to fracture. 
(1)
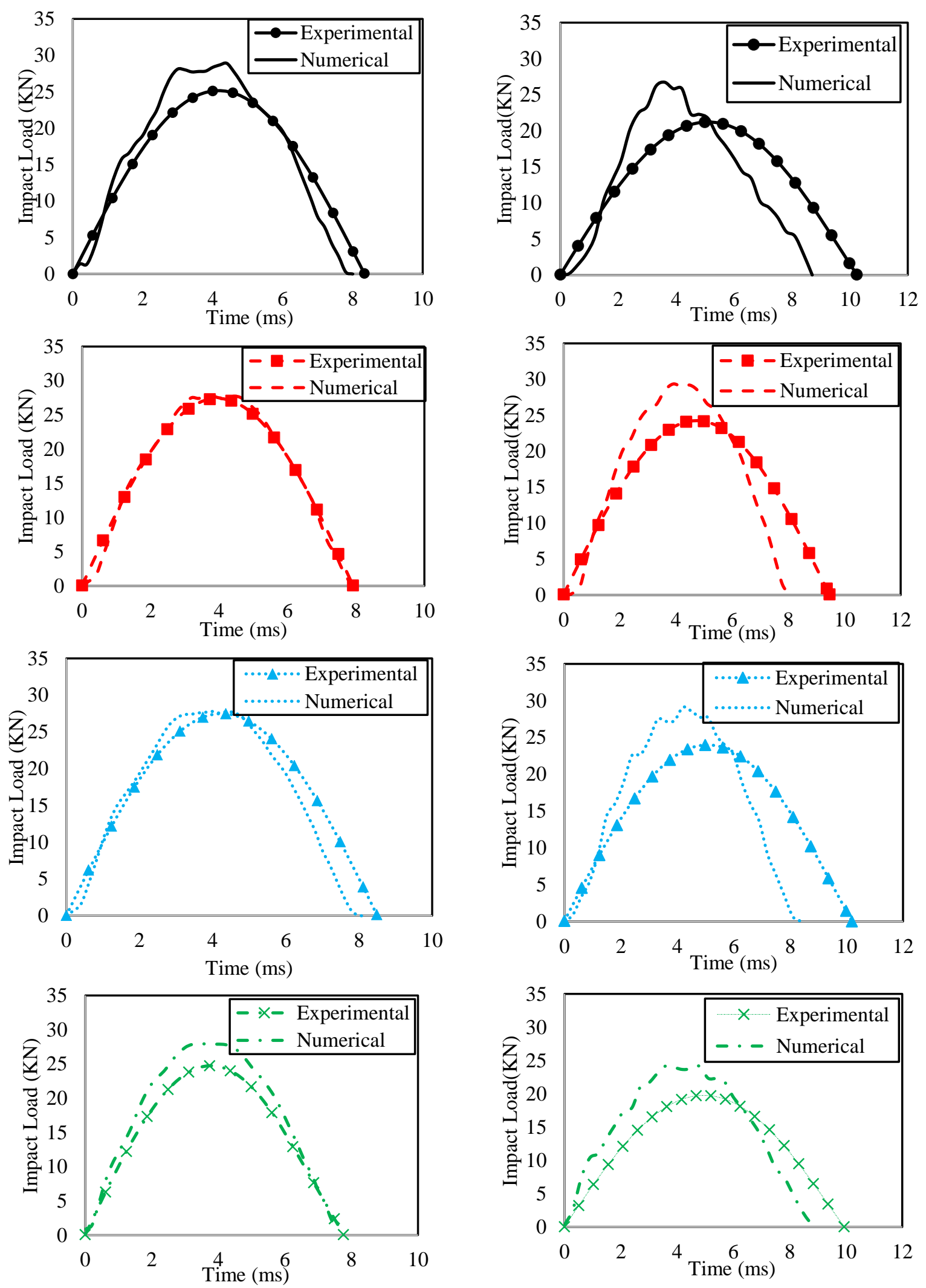

(a)

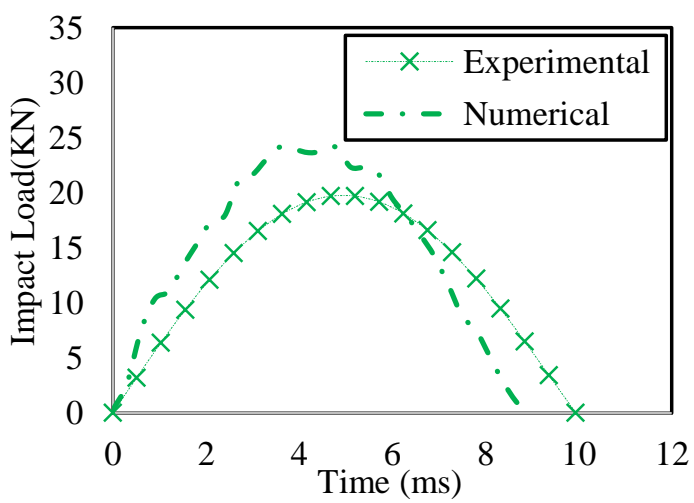

(b)

Figure 7. Comparison of the experimental and numerical impact load-time response of (1) PPSCGF, (2) PPLGF, (3) PPLGFY, (4) neat PP fixation plate systems for $70 \mathrm{~J}$ impact energy in (a) stable and (b) unstable bone fracture. (The values are the mean value, and the standard deviation (SD) is $5 \%$ on average.) 
In the impact FE simulation, the predicted load-time value has some errors with the experimental values ranging between $20-30 \%$ that could increase up to $30-40 \%$ [26]. Hence, there is an acceptable correlation between numerical and experimental results.

In general, several factors such as simplification in modeling (geometry and mechanical properties), errors of the measurement system (accelerometer), and environmental conditions could be the causes of mismatches between numerical and experimental results. However, due to the little difference between numerical and experimental results, it can be concluded that the process of solving in the software has been done correctly and the output results of the software can be trusted.

\section{Results}

The transmitted maximum forces resulted from the finite element simulation for different fracture gaps (i.e., 1, 5, and $10 \mathrm{~mm}$ ), and the various projectile impact energies (i.e., 35, 70, and $140 \mathrm{~J}$ ) are illustrated in table 3 . The effects of the fixation plate mechanical properties through the axial direction and the length of the fracture site can be observed in transmitted peak force values. The maximum force increased nonlinearly by the increase of the impact energy level. Based on the trend of all four materials, it can be concluded that the stiffer structure (PPLGF) has the highest maximum force at each energy level, which reduces the damping effect of the structure.

Table 3. Comparison of transmitted peak force $(\mathrm{kN})$ to different fixation plate systems in various impact energies and fracture gaps.

\begin{tabular}{|c|c|c|c|c|c|c|c|c|c|}
\cline { 2 - 11 } \multicolumn{1}{c|}{} & \multicolumn{3}{c|}{$1 \mathrm{~mm}$} & \multicolumn{3}{c|}{$5 \mathrm{~mm}$} & \multicolumn{3}{c|}{$10 \mathrm{~mm}$} \\
\cline { 2 - 11 } & $35 \mathrm{~J}$ & $70 \mathrm{~J}$ & $140 \mathrm{~J}$ & $35 \mathrm{~J}$ & $70 \mathrm{~J}$ & $140 \mathrm{~J}$ & $35 \mathrm{~J}$ & $70 \mathrm{~J}$ & $140 \mathrm{~J}$ \\
\hline PPSCGF & 18.7 & 28.9 & 37.9 & 19.9 & 28.2 & 36.0 & 17.2 & 26.7 & 35.2 \\
\hline PPLGF & 19.2 & 27.7 & 37.7 & 19.6 & 28.2 & 36.4 & 19.9 & 29.1 & 35.5 \\
\hline PPLGFY & 19.2 & 27.7 & 37.6 & 19.2 & 28.2 & 37.1 & 19.0 & 29.1 & 34.3 \\
\hline Neat PP & 19.2 & 27.9 & 37.1 & 19.1 & 28.3 & 36.6 & 16.4 & 24.1 & 34.6 \\
\hline
\end{tabular}


To evaluate the results more accurately, the impact duration of different fixation plate systems in various impact energies and fracture gaps are shown in table 4. Although each structure impact duration varied at different energies, a constant trend was observed at the two lower energy levels, which can be related to the lack of the diffusion cracks in the plate and complete failure of the fixation plates. However, due to the FE process of removing elements in the fixation plates, which reduces the structures stiffness, the impact duration is slightly irregular for higher energy.

Table 4. Comparison of different fixation plate systems impact duration (ms) in various impact energies and fracture gaps.

\begin{tabular}{|c|c|c|c|c|c|c|c|c|c|}
\cline { 2 - 11 } \multicolumn{1}{c|}{} & \multicolumn{3}{c|}{$1 \mathrm{~mm}$} & \multicolumn{3}{c|}{$5 \mathrm{~mm}$} & \multicolumn{3}{c|}{$10 \mathrm{~mm}$} \\
\cline { 2 - 11 } & $35 \mathrm{~J}$ & $70 \mathrm{~J}$ & $140 \mathrm{~J}$ & $35 \mathrm{~J}$ & $70 \mathrm{~J}$ & $140 \mathrm{~J}$ & $35 \mathrm{~J}$ & $70 \mathrm{~J}$ & $140 \mathrm{~J}$ \\
\hline PPSCGF & 7.7 & 7.8 & 8 & 8.4 & 9 & 8.5 & 8 & 8.7 & 8.7 \\
\hline PPLGF & 7.8 & 8 & 7.8 & 7.75 & 8.75 & 8.5 & 8.91 & 8.1 & 9.5 \\
\hline PPLGFY & 7.8 & 8 & 7.8 & 8.25 & 8.5 & 8.5 & 8.25 & 8.4 & 10.8 \\
\hline Neat PP & 7.8 & 7.8 & 8 & 8 & 9.25 & 8.5 & 9.57 & 9.3 & 8.5 \\
\hline
\end{tabular}

It should be noted that strain gauges installed on a human leg recorded the impact duration of 40 to 170 milliseconds $[27,28]$. This discrepancy can be attributed to the lack of damping effects due to muscle mass and soft tissue in the current study. The research results $[27,28]$ showed that soft tissues energy absorption plays a vital role in reducing the applied impact load.

Due to the rapid occurrence of plate failure in unstable bone fracture, the recorded images cannot be applicable for investigating the fixation plate systems strain patterns. The equivalent Von-Mises strain fields of the fixation plate systems for stable bone fracture during impact loading are shown in figure 8. Equivalent Von-Mises strain was chosen because it represents an accurate state of strain in each node of the plate and is always positive. 

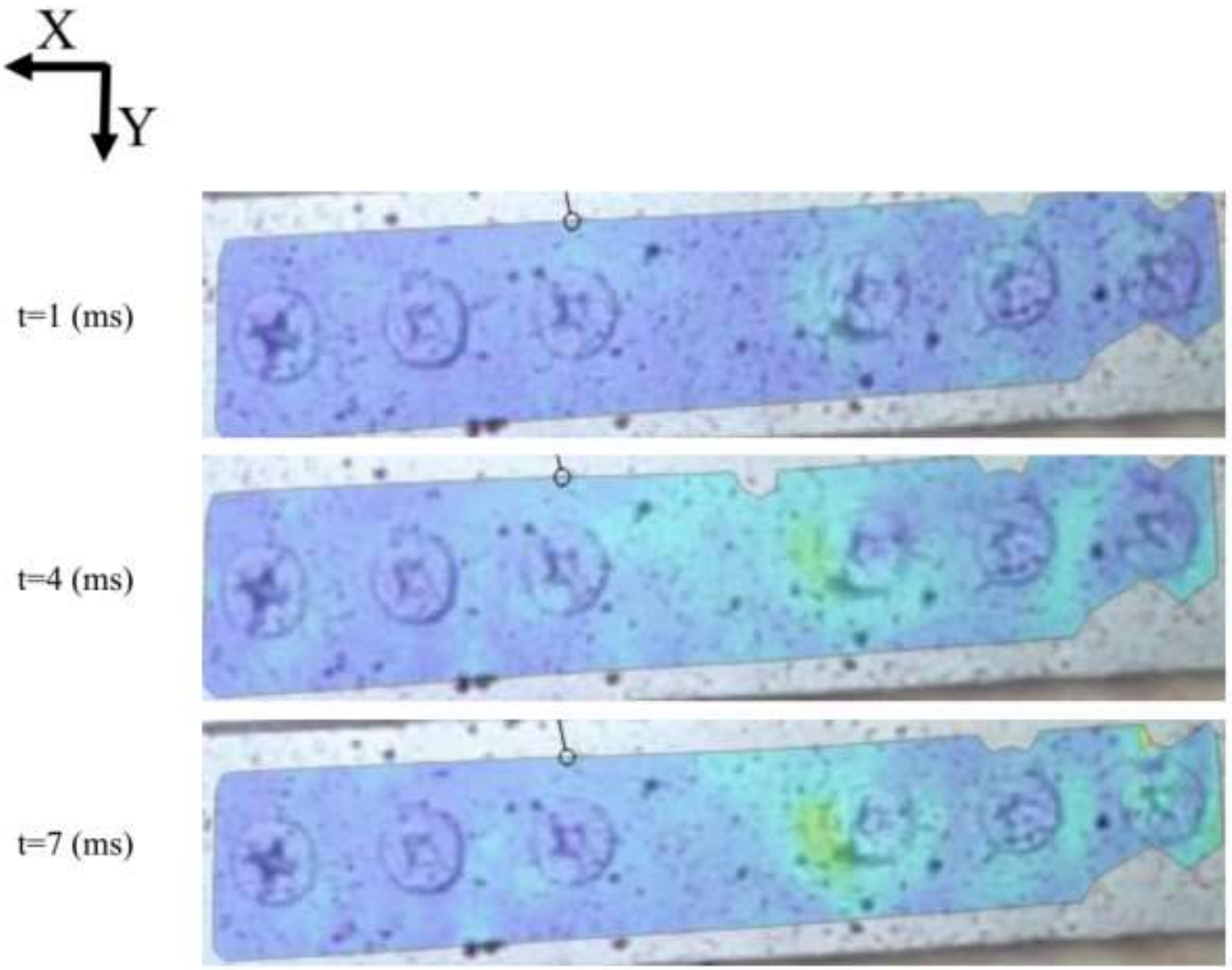

(a)
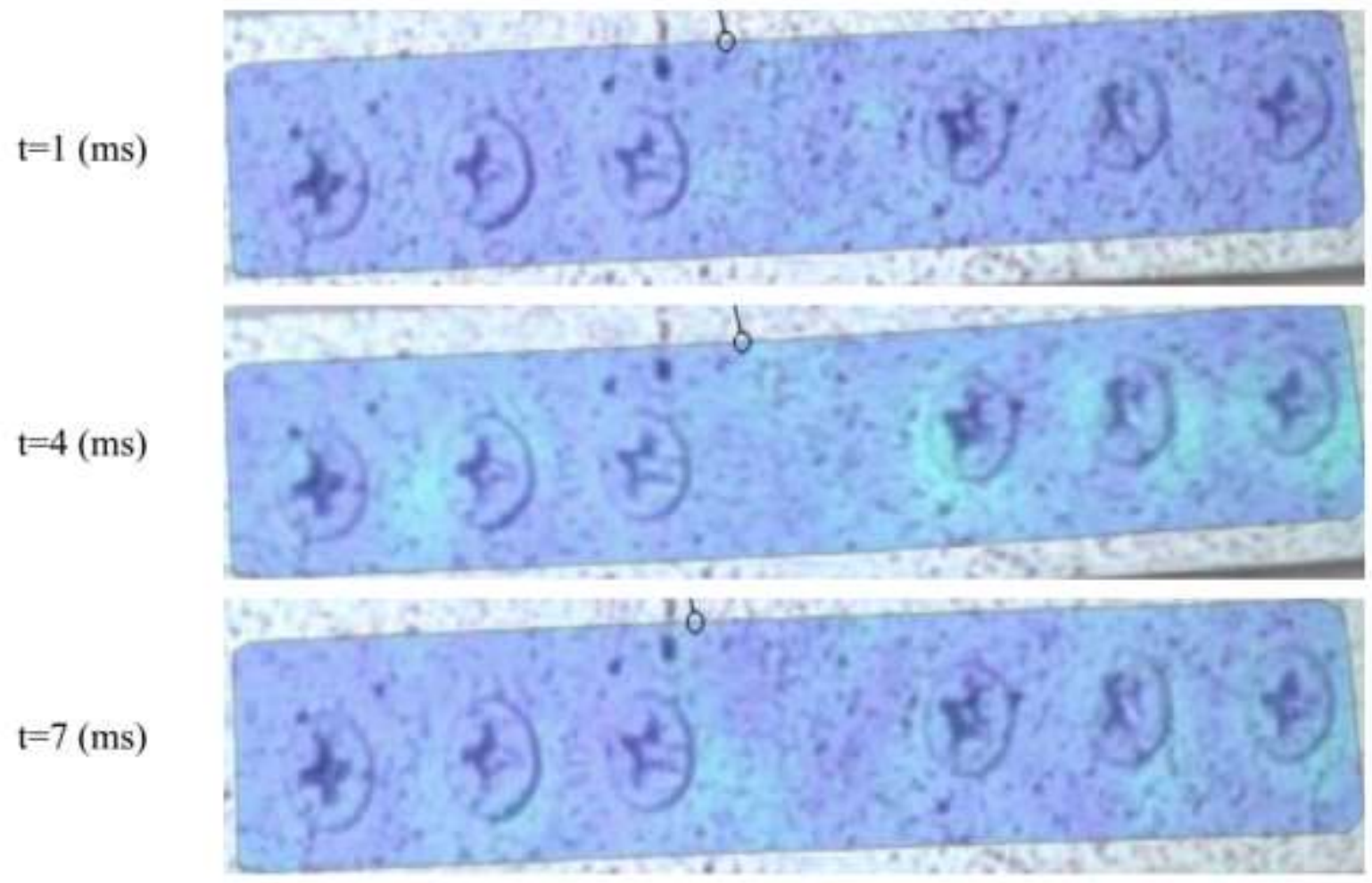

(b) 


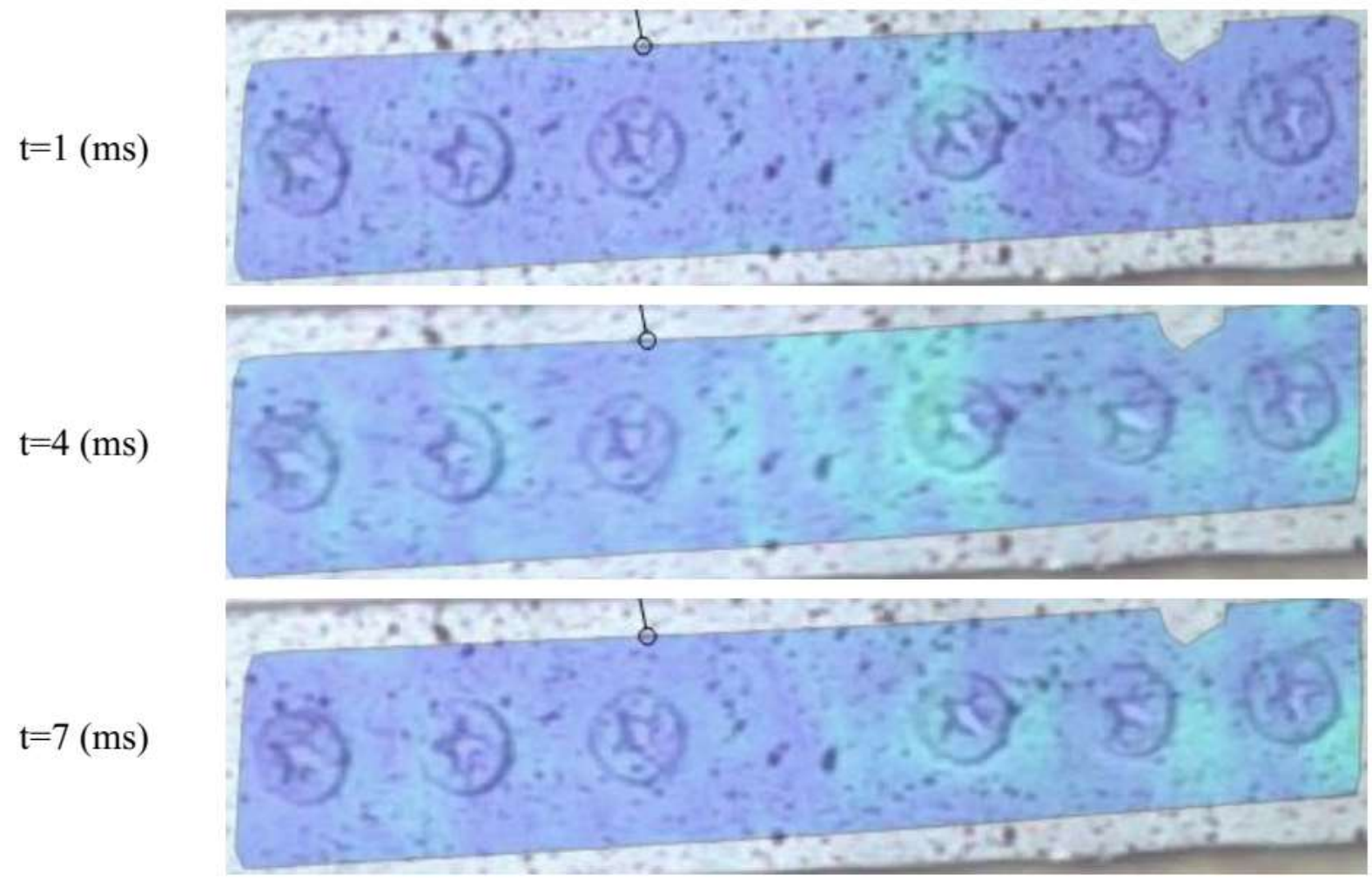

(c)
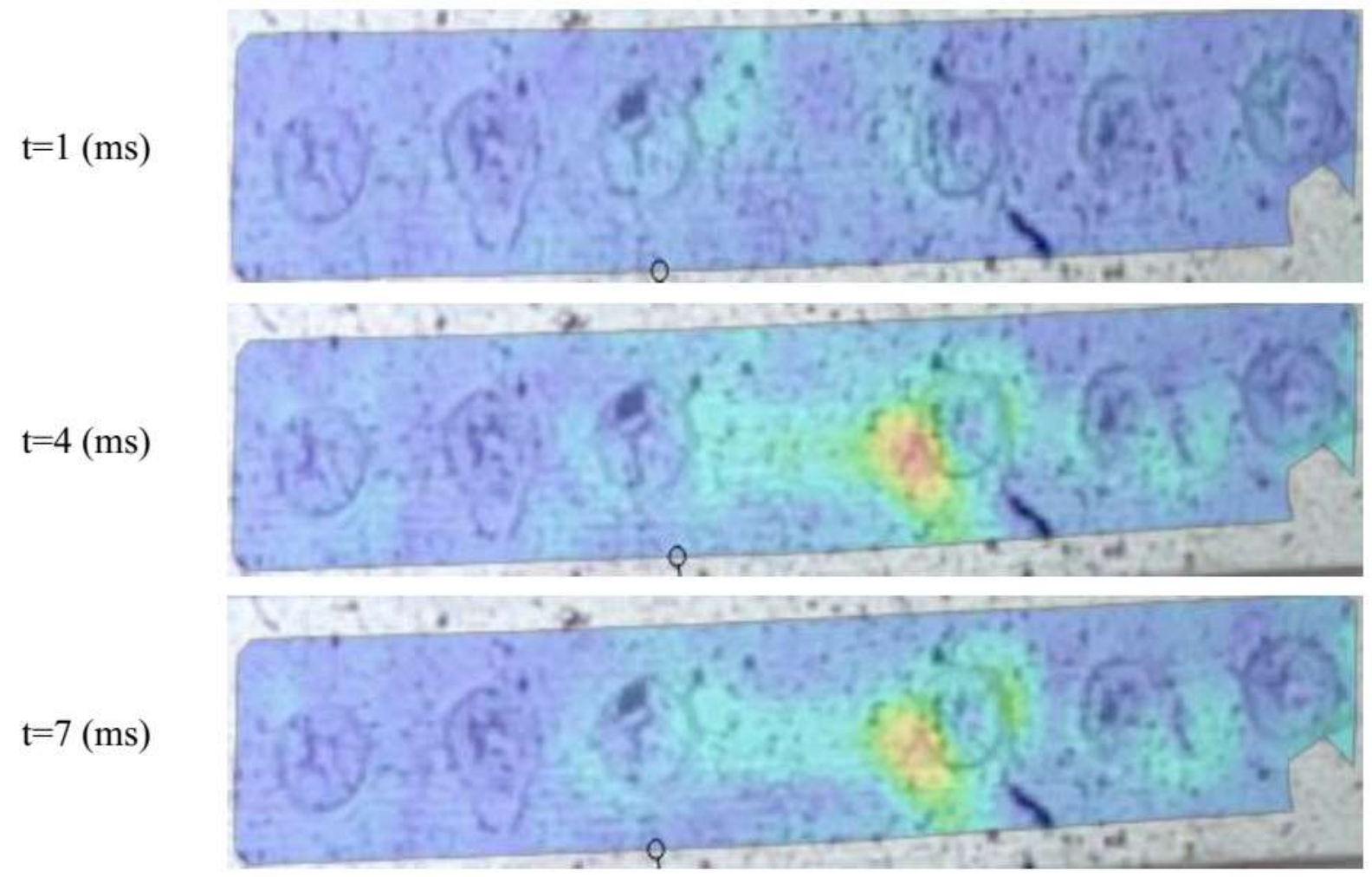

(d)

Figure 8. DIC full-field images of equivalent Von-Mises strain of different fixation plate systems for $70 \mathrm{~J}$ impact energy in stable bone fracture during loading and unloading; (a) .PPSCGF, (b) PPLGF, (c) PPLGFY, and (d) neat PP. 
To further investigate the impact-induced strain of the fixation plate systems, the equivalent Von-Mises strain values of each fixation plate system's central element (see figure 6-c) for 70 $\mathrm{J}$ impact energy in stable bone fracture during loading and unloading are shown in figure 9.

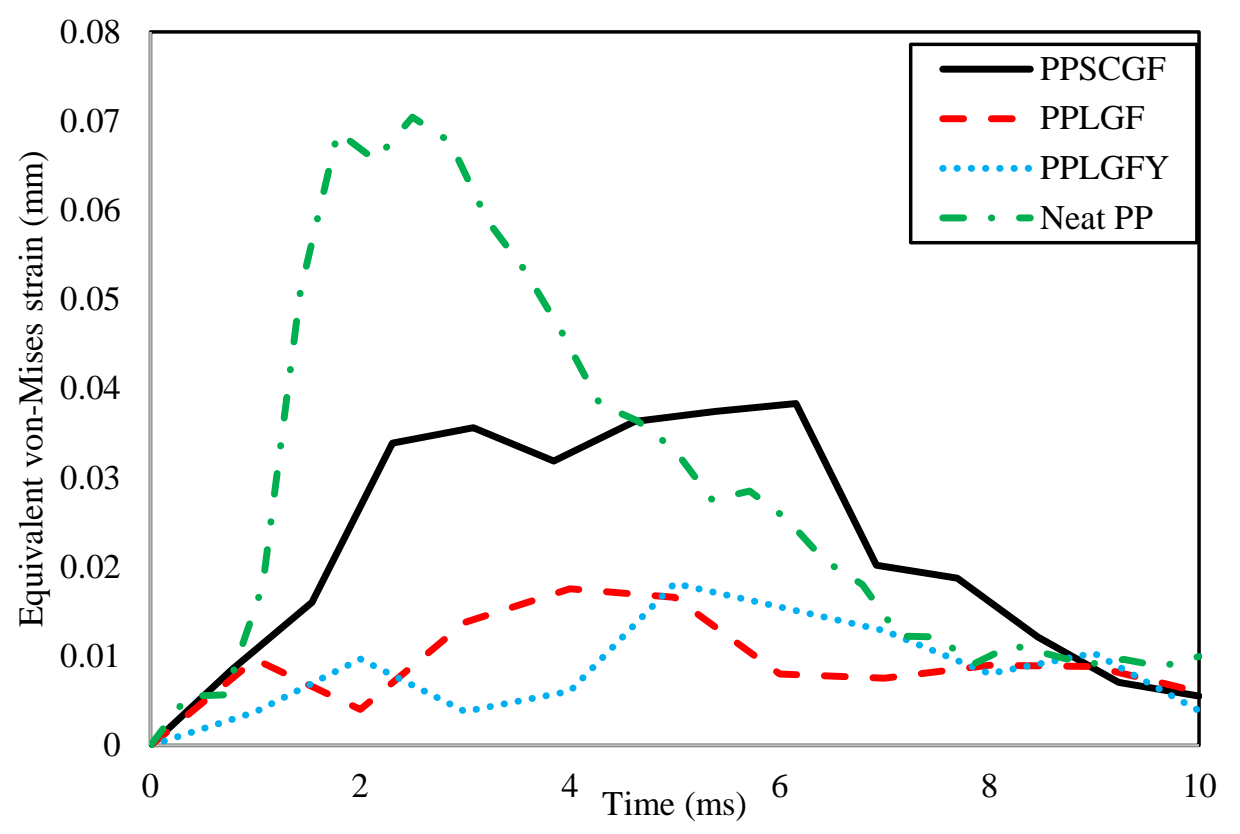

Figure 9. Comparison of equivalent Von-Mises strain of different fixation plate systems center element for $70 \mathrm{~J}$ impact energy in stable bone fracture during loading and unloading.

The FE analysis provides a good vision into the stress distribution of fixation plates, which is needed to evaluate composites use as fixation plate materials. Longitudinal and flexural stress and the stress concentration reduce the mechanical plate capabilities during the impact loading. The Von-Mises stress distribution of all fixation plates at peak force for 35,70 , and $140 \mathrm{~J}$ impact energies are shown in figures 10-12. Moreover, the effects of the fracture gap values on the predicted Von-Mises stresses are shown in figures 10-12. The insertion and direction of loading and the assembly complexity cause a non-uniform and asymmetric stress distribution in plates. 


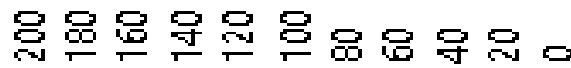

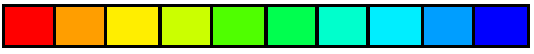

$1 \mathrm{~mm}$

(a)
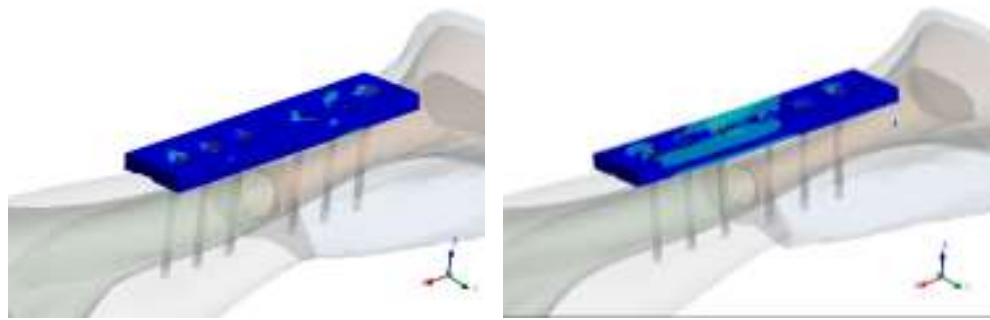

$5 \mathrm{~mm}$

$10 \mathrm{~mm}$

(b)
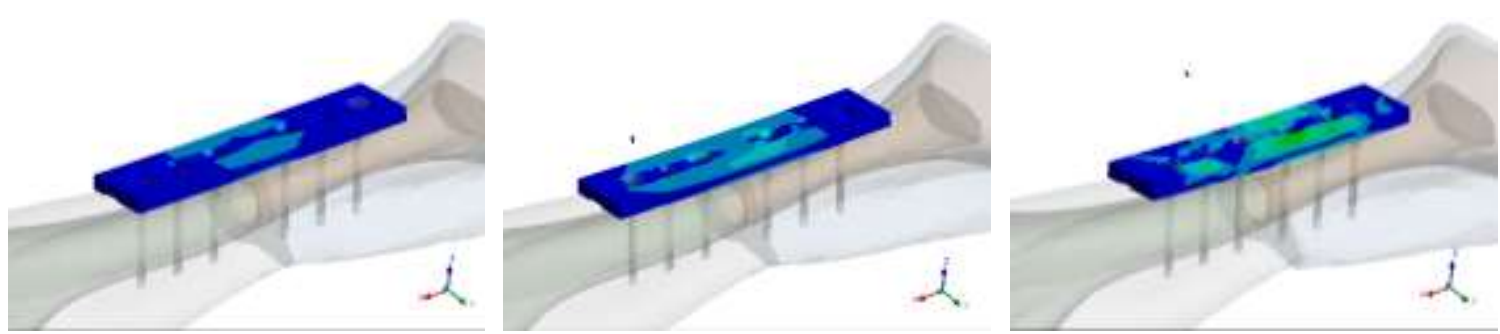

(c)
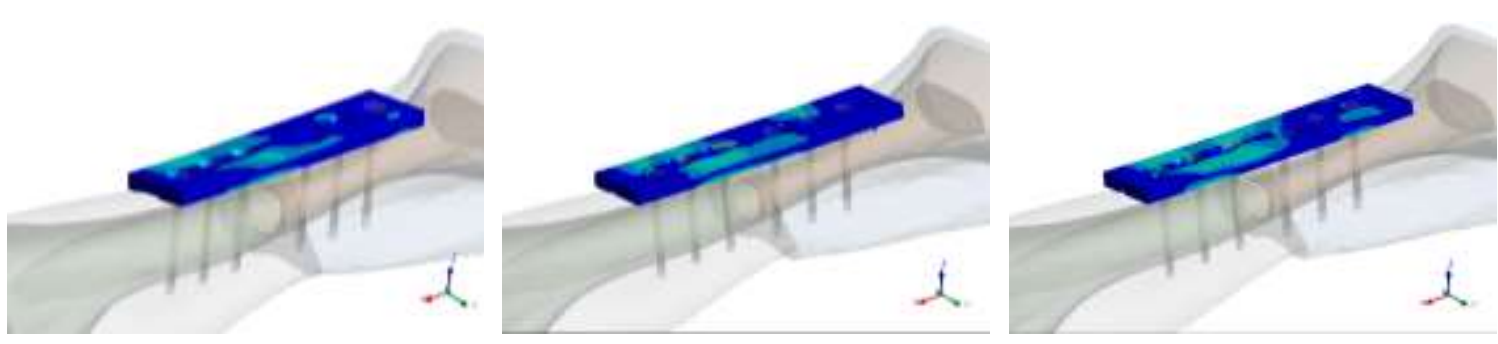

(d)
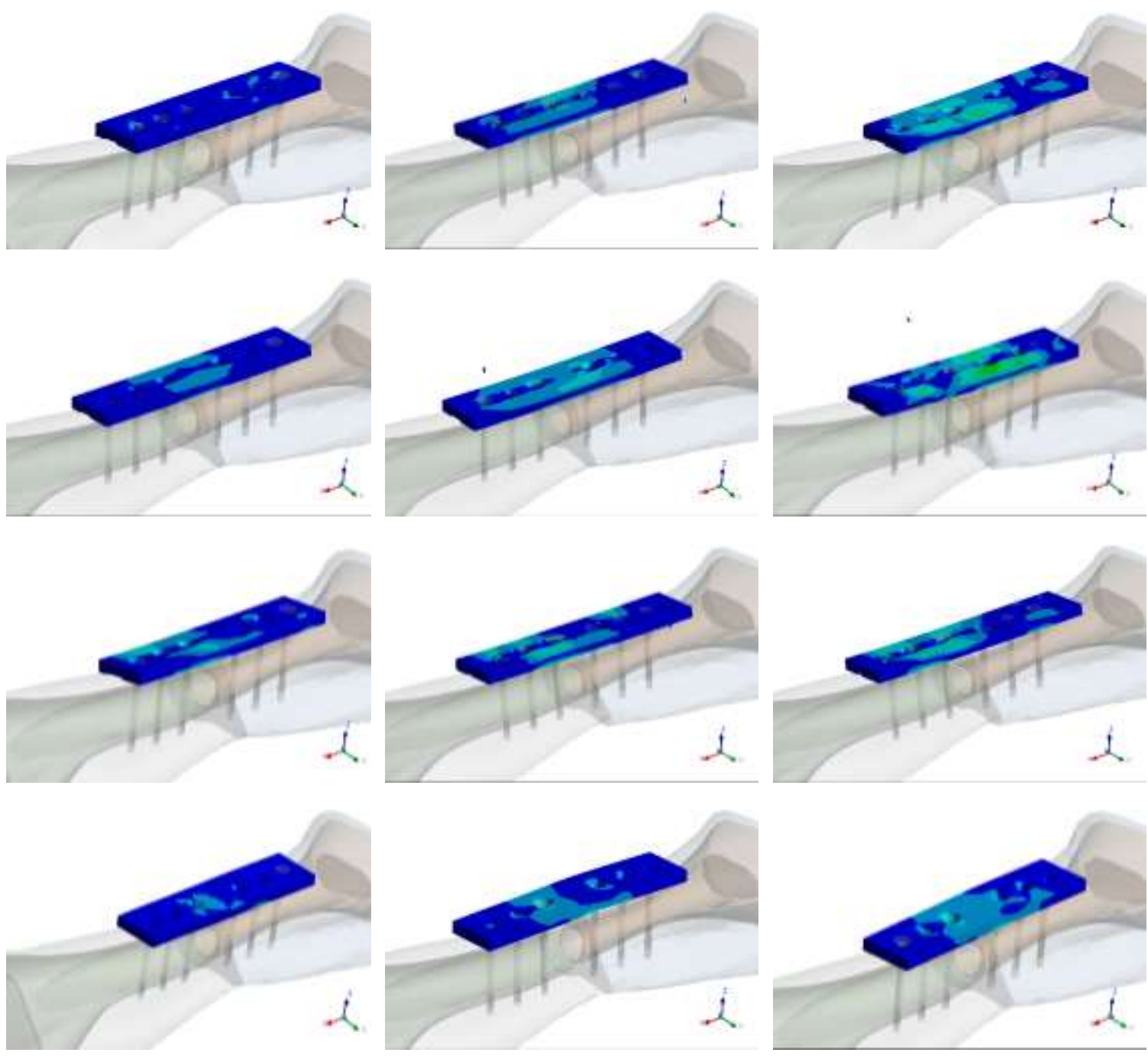

Figure 10. Comparison of equivalent Von-Mises stress of the fixation plate at peak force for $35 \mathrm{~J}$ impact energy in various fracture gaps (1, 5, and $10 \mathrm{~mm}$ ); (a) PPSCGF, (b) PPLGF, (c) PPLGFY, and (d) Neat PP. 


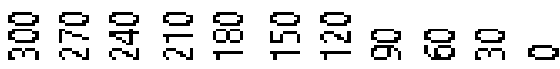

\section{\begin{tabular}{|l|l|l|l|l|l|l|l|l|l|}
\hline & & & & & & & & & \\
\hline
\end{tabular}}

$1 \mathrm{~mm}$

(a)
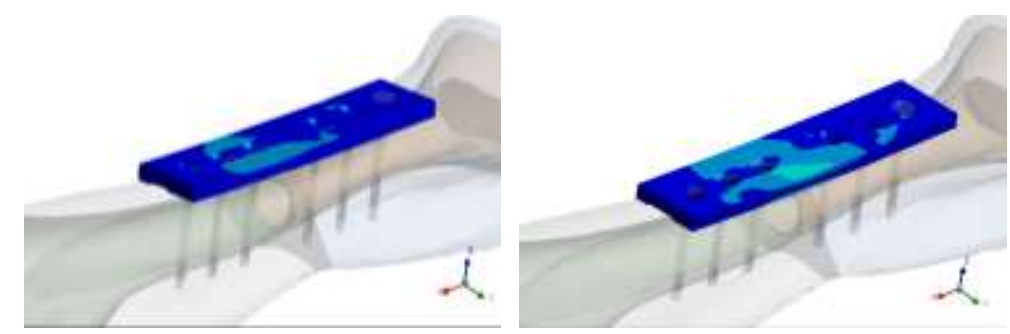

(b)
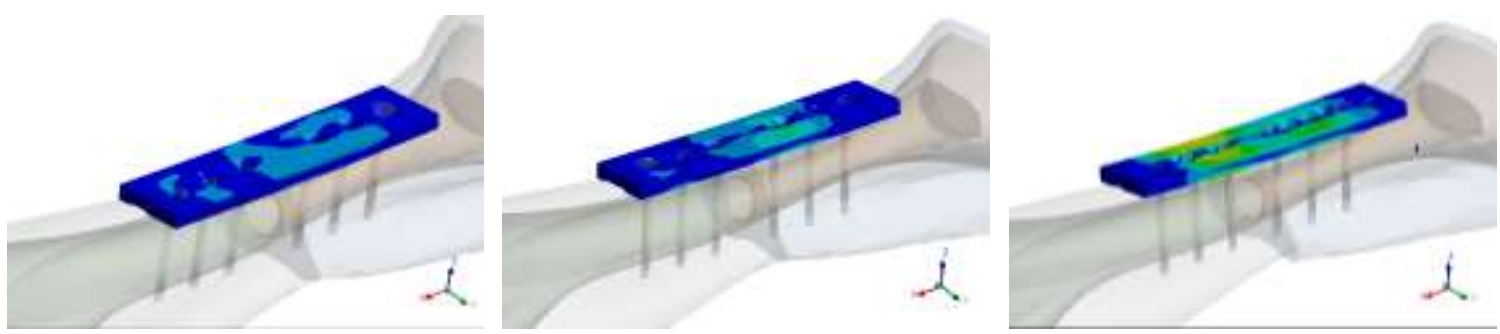

(c)
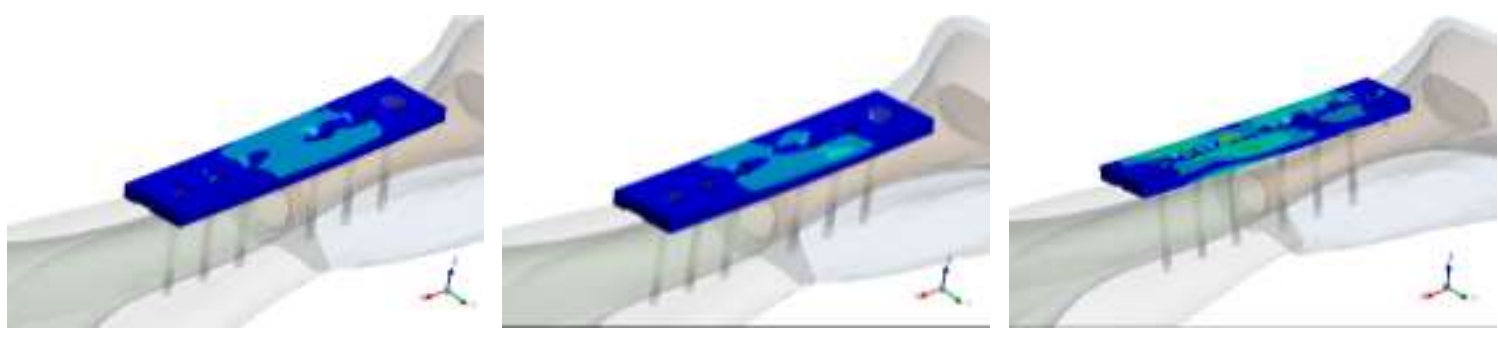

(d)

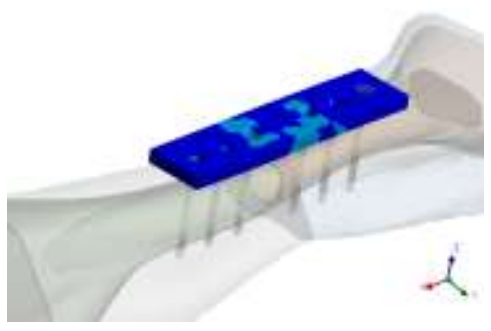

$10 \mathrm{~mm}$
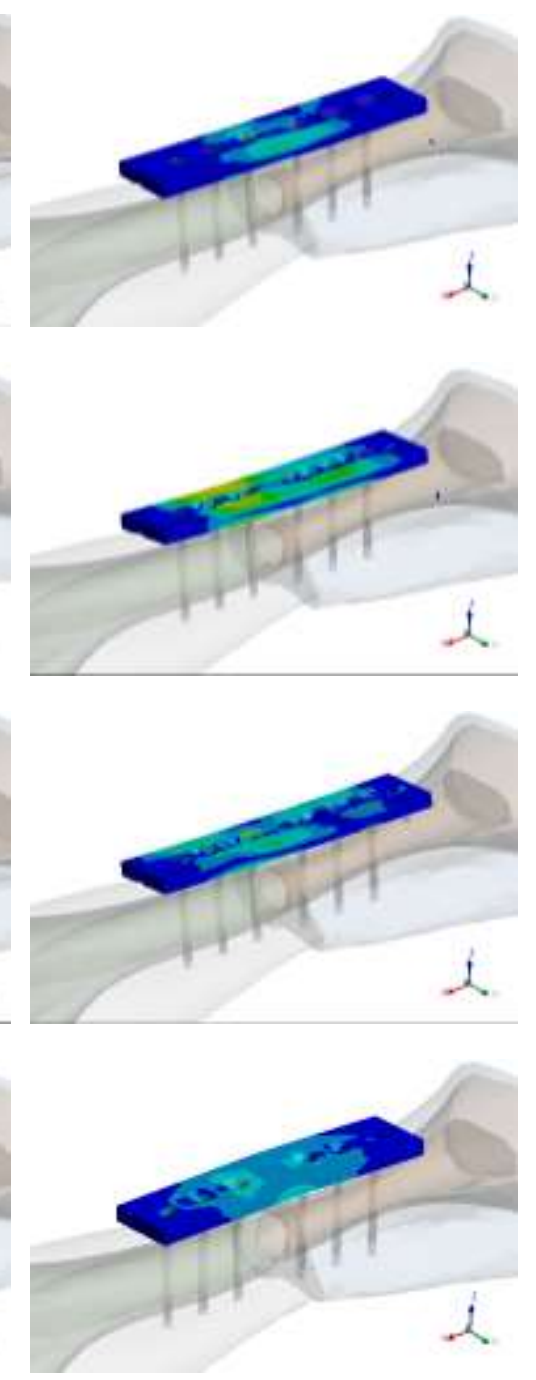

Figure 11. Comparison of equivalent Von-Mises stress of the fixation plate at peak force for $70 \mathrm{~J}$ impact energy in various fracture gaps (1, 5, and $10 \mathrm{~mm}$ ); (a) PPSCGF, (b) PPLGF, (c) PPLGFY, and (d) Neat PP. 


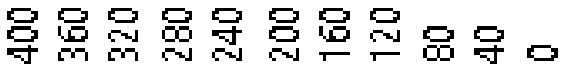

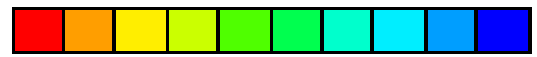

$1 \mathrm{~mm}$

(a)
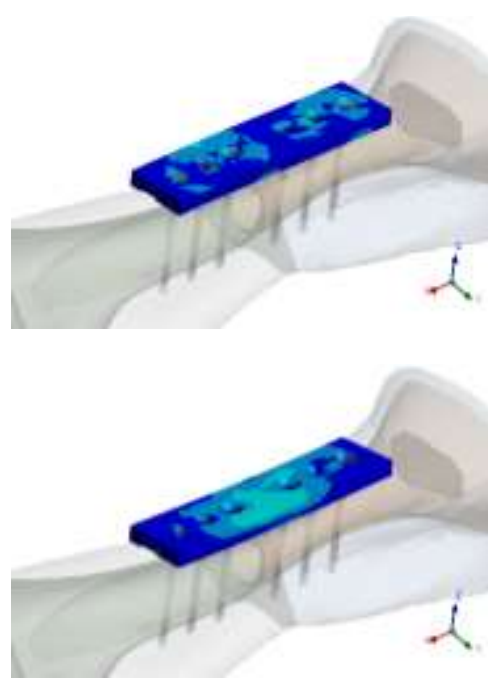

(b)

(c)
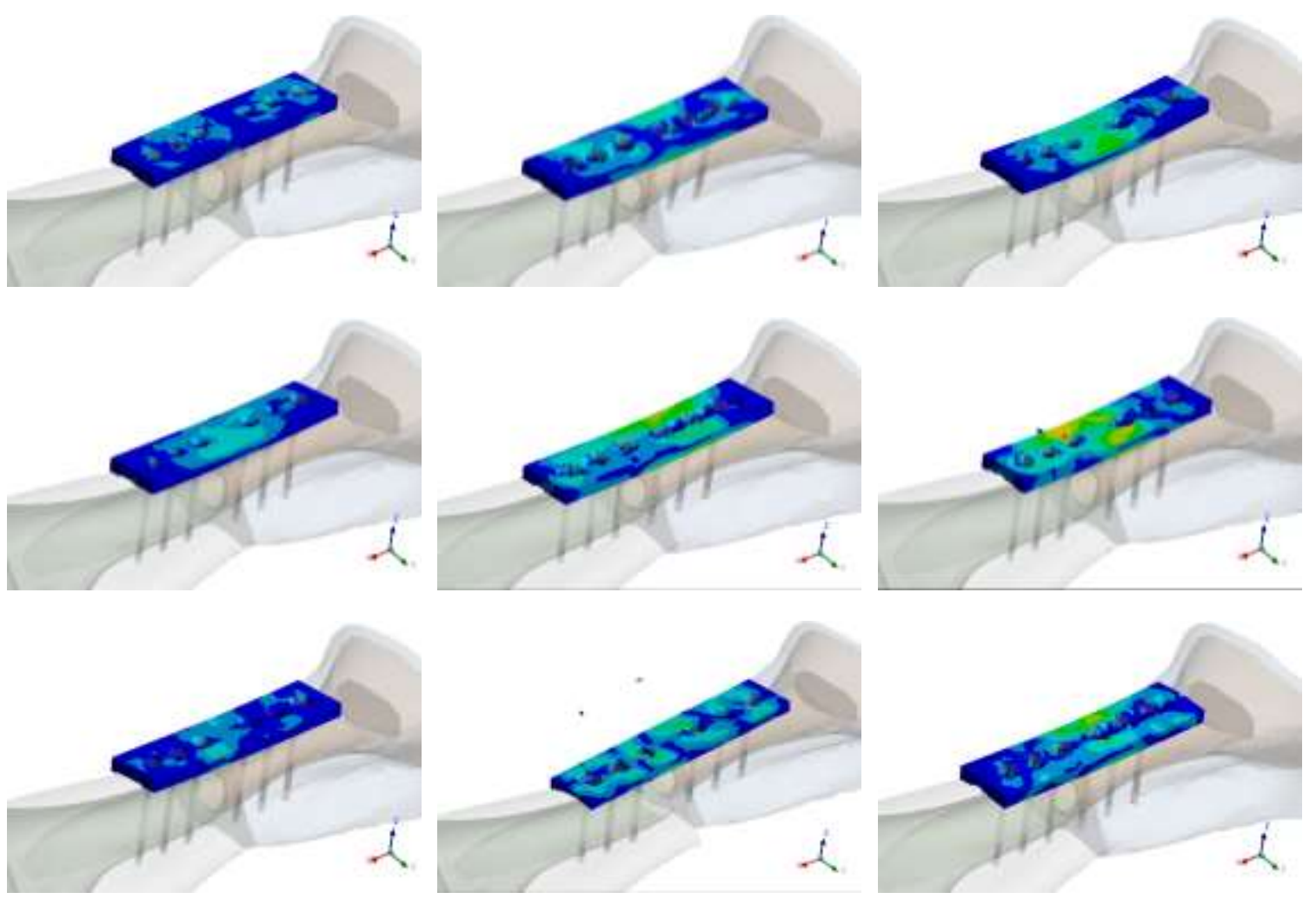

(d)
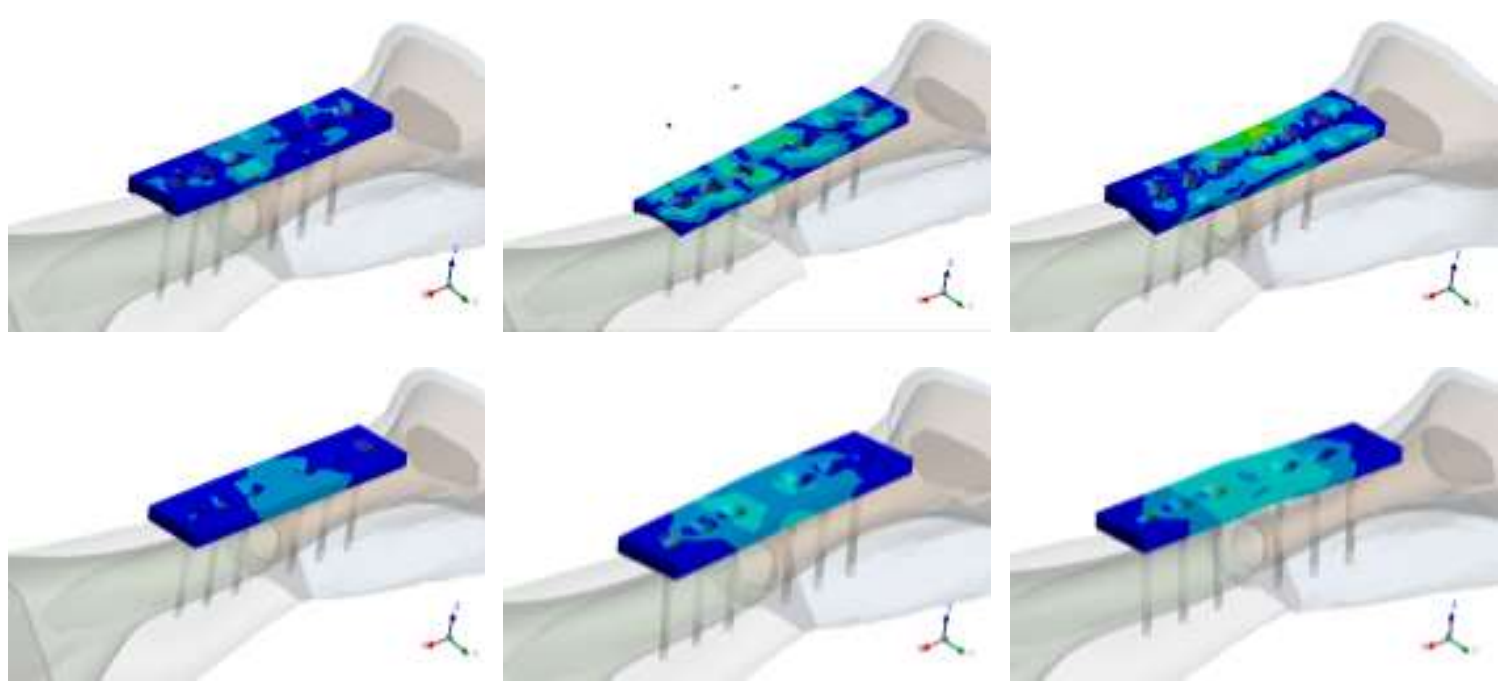

Figure 12. Comparison of equivalent Von-Mises stress of the fixation plate at peak force for $140 \mathrm{~J}$ impact energy in various fracture gaps (1, 5, and $10 \mathrm{~mm}$ ); (a) PPSCGF, (b) PPLGF, (c) PPLGFY, and (d) Neat PP.

For the more detailed investigation, tables 5-7 show the mean values of equivalent Von-Mises stress for fractured bone, plate, and screws at peak force in various impact energies and fracture gaps. 
Table 5. Comparison of equivalent Von-Mises stress mean values (MPa) of the fractured bone at peak force in various impact energies and fracture gaps.

\begin{tabular}{|c|c|c|c|c|c|c|c|c|c|}
\cline { 2 - 11 } \multicolumn{1}{c|}{} & \multicolumn{3}{c|}{$1 \mathrm{~mm}$} & \multicolumn{3}{c|}{$5 \mathrm{~mm}$} & \multicolumn{3}{c|}{$10 \mathrm{~mm}$} \\
\cline { 2 - 11 } & $35 \mathrm{~J}$ & $70 \mathrm{~J}$ & $140 \mathrm{~J}$ & $35 \mathrm{~J}$ & $70 \mathrm{~J}$ & $140 \mathrm{~J}$ & $35 \mathrm{~J}$ & $70 \mathrm{~J}$ & $140 \mathrm{~J}$ \\
\hline PPSCGF & 146 & 218 & 286 & 146 & 211 & 277 & 148 & 219 & 283 \\
\hline PPLGF & 140 & 213 & 286 & 136 & 212 & 275 & 121 & 202 & 268 \\
\hline PPLGFY & 142 & 215 & 287 & 145 & 212 & 275 & 146 & 210 & 260 \\
\hline Neat PP & 144 & 216 & 284 & 142 & 210 & 277 & 125 & 181 & 263 \\
\hline
\end{tabular}

Table 6. Comparison of equivalent Von-Mises stress mean values (MPa) of the plate at peak force in various impact energies and fracture gaps.

\begin{tabular}{|c|c|c|c|c|c|c|c|c|c|}
\cline { 2 - 11 } \multicolumn{1}{c|}{} & \multicolumn{3}{c|}{$1 \mathrm{~mm}$} & \multicolumn{3}{c|}{$5 \mathrm{~mm}$} & \multicolumn{3}{c|}{$10 \mathrm{~mm}$} \\
\cline { 2 - 11 } & $35 \mathrm{~J}$ & $70 \mathrm{~J}$ & $140 \mathrm{~J}$ & $35 \mathrm{~J}$ & $70 \mathrm{~J}$ & $140 \mathrm{~J}$ & $35 \mathrm{~J}$ & $70 \mathrm{~J}$ & $140 \mathrm{~J}$ \\
\hline PPSCGF & 49 & 58 & 64 & 77 & 88 & 86 & 105 & 92 & 85 \\
\hline PPLGF & 221 & 235 & 290 & 200 & 218 & 290 & 212 & 167 & 157 \\
\hline PPLGFY & 114 & 137 & 197 & 123 & 157 & 197 & 217 & 176 & 143 \\
\hline Neat PP & 45 & 54 & 51 & 45 & 52 & 59 & 50 & 55 & 56 \\
\hline
\end{tabular}

Table 7. Comparison of equivalent Von-Mises stress mean values (MPa) of the screws at peak force in various impact energies and fracture gaps.

\begin{tabular}{|c|c|c|c|c|c|c|c|c|c|}
\cline { 2 - 11 } \multicolumn{1}{c|}{} & \multicolumn{3}{c|}{$1 \mathrm{~mm}$} & \multicolumn{3}{c|}{$5 \mathrm{~mm}$} & \multicolumn{3}{c|}{$10 \mathrm{~mm}$} \\
\cline { 2 - 11 } & $35 \mathrm{~J}$ & $70 \mathrm{~J}$ & $140 \mathrm{~J}$ & $35 \mathrm{~J}$ & $70 \mathrm{~J}$ & $140 \mathrm{~J}$ & $35 \mathrm{~J}$ & $70 \mathrm{~J}$ & $140 \mathrm{~J}$ \\
\hline PPSCGF & 99 & 157 & 218 & 105 & 165 & 233 & 115 & 191 & 270 \\
\hline PPLGF & 95 & 166 & 260 & 109 & 183 & 244 & 178 & 180 & 235 \\
\hline PPLGFY & 95 & 167 & 233 & 107 & 173 & 242 & 127 & 191 & 266 \\
\hline Neat PP & 128 & 188 & 238 & 222 & 237 & 282 & 222 & 264 & 341 \\
\hline
\end{tabular}

The failure modes of the fixation plate systems in stable and unstable bone fractures for $70 \mathrm{~J}$ impact energy are illustrated in figures 13 and 14. The projectile impact on the bone created compressive and tensile stress waves, which propagated and reached the fixation plate system. Due to the different speeds of the wave propagation, when the waves reach the plates free or clamp surfaces, different movements of compressive and tensile stress waves occur. If these 
waves reach the tensile and compressive strength of the fixation plate material, cracks will initiate along the screw holes, and the plate will fail due to the strain concentration.

(a)
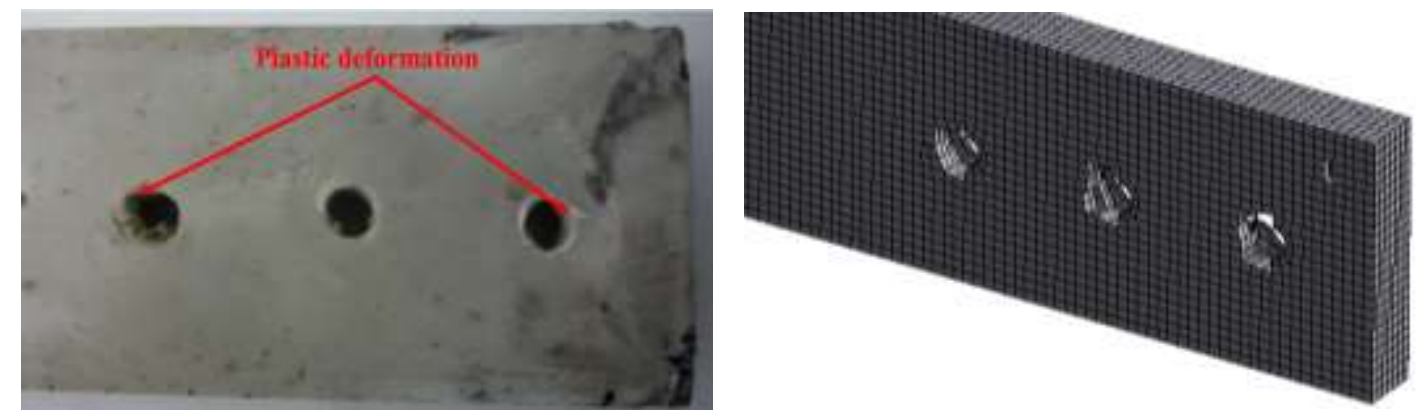

(Experimental)

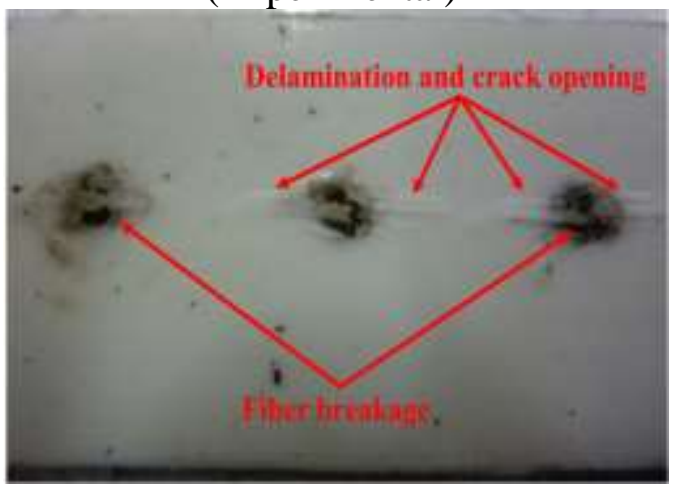

(Experimental)

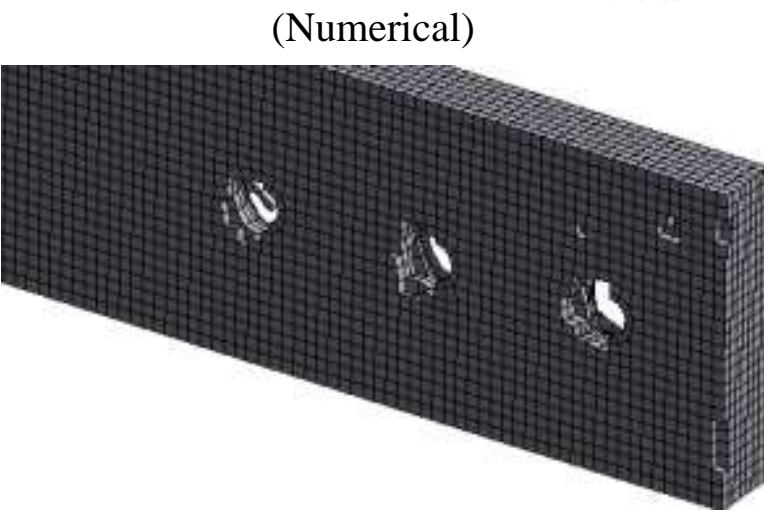

(Numerical)

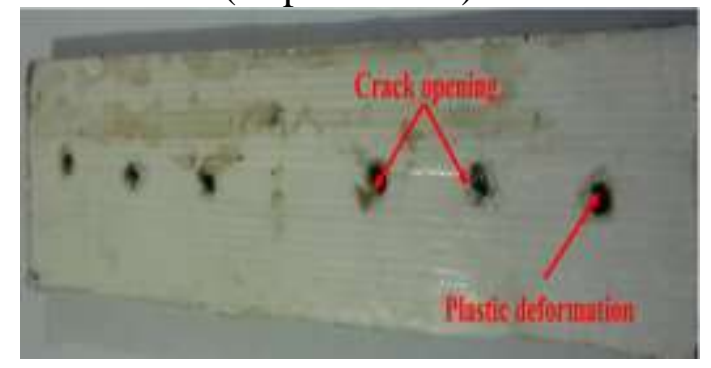

(Experimental)

(Numerical)

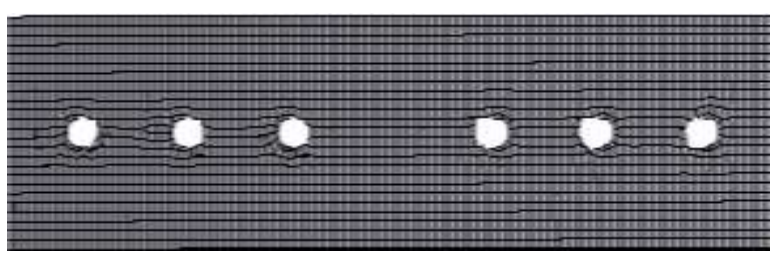

Figure 13. Comparison of predicted failure mechanisms in numerical method with experimental cases in stable bone fracture for $70 \mathrm{~J}$ impact energy; (a) PPSCGF, (b) PPLGF, and (c) PPLGFY. 
(a)

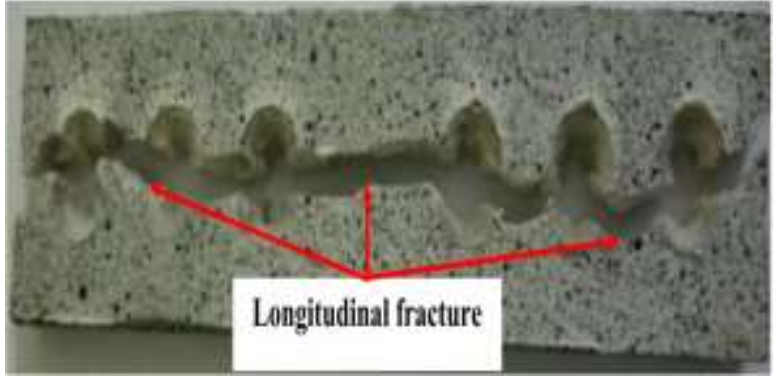

(Experimental)

(b)

(c)

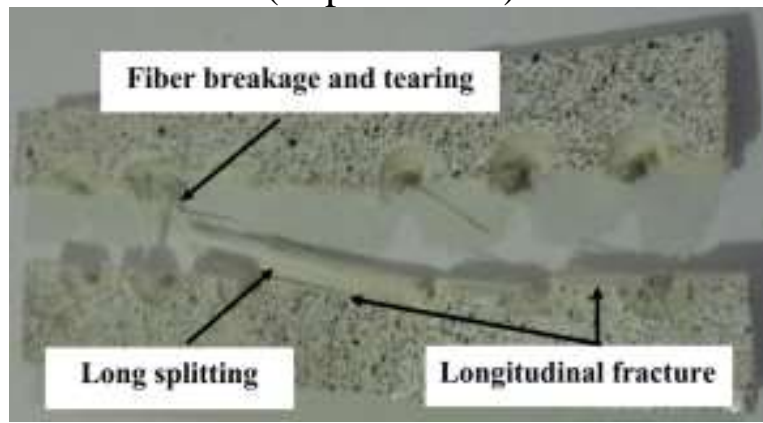

(Experimental)
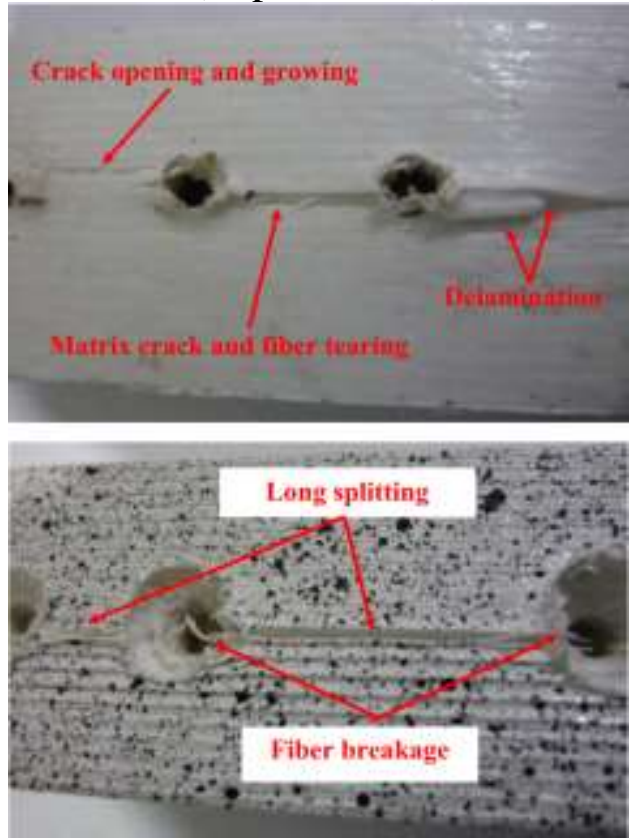

(Experimental)

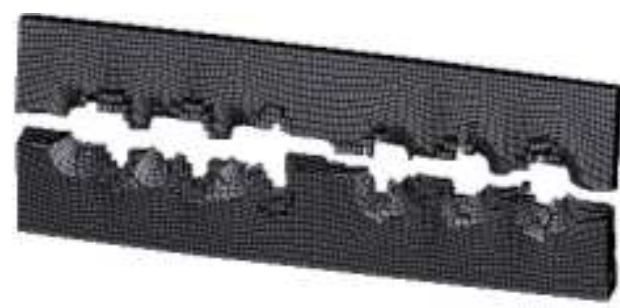

(Numerical)

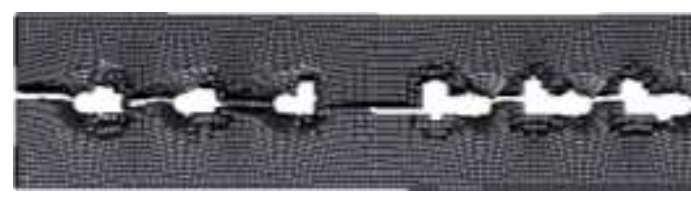

(Numerical)

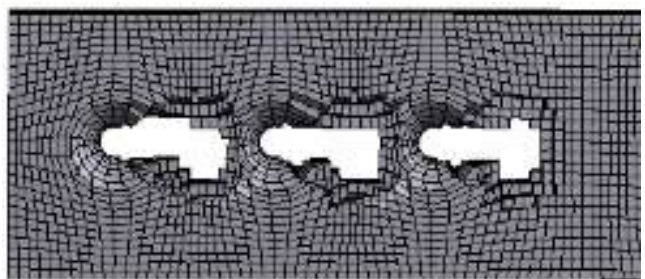

(Numerical)

Figure 14. Comparison of predicted failure mechanisms in numerical method with experimental cases in unstable bone fracture for $70 \mathrm{~J}$ impact energy; (a) PPSCGF, (b) PPLGF, and (c) PPLGFY.

\section{Discussion}

\subsection{Load-time response of fixation plate structures}

Generally, as can be seen in figure 7 and tables 3 and 4, the neat PP shows less transmitted peak force and more impact duration due to its low modulus and plastic behavior. In other 
words, owing to the reduction of transmitted peak force by the distribution of impact energy over a longer period, the material with more plastic and low rigid property can act as a shock absorber. The low-rigidity plate system mentioned advantages provide the possibility of sufficient interfragmentary movement at the fracture site [10]. Since the existence of the callus zone adequate interfragmentary movement is essential in the healing process, the low-rigidity plate systems may cause a faster healing process. This is one of the most important reasons for modifying stiffer plates to replace low-rigidity composite plates. Therefore, a low-rigidity plate system reduces impact loads and can lead to sufficient interfragmentary motion for bone fracture healing [10]. It can also overcome the high failure rate of bone fractures in clinical applications with an increase of their resistance to loosening; however, this system has low stiffness in bending and twisting compared to conventional plates. Low torsional stiffness can lead to excessive shear movement in the fracture site, delaying the healing process [29]. Therefore, to design a proper composite fixation plate system, the results of their static and quasi-static loading must be carefully evaluated in addition to the impact loading effects on them. An axial quasi-static compression test was conducted on fixation plate structures to determine the fixation plate systems' overall stiffness and failure load. The distal cylindrical pot was fixed in all directions while the compressive force was applied with a speed of 2 $\mathrm{mm} / \mathrm{sec}$, and force was kept until failure occurred. Figure 15 shows a comparative diagram of the fixation plate structures overall stiffness in the stable and unstable fracture under axial compression loading.

There is a two-phase stiffness pattern (initial and second phase) in quasi-static loading. The second phase stiffness is the stiffness that happens after the fractured ends come into contact. Since the second-phase stiffness does not represent an actual structural stability measure, the initial phase is usually analyzed and compared. In the stable bone fracture, the stiffness of PPLGF, PPLGFY, and PPSCGF fixation plate structures are $3.23 \pm 0.1 \mathrm{kN} / \mathrm{mm}, 1.39 \pm 0.1$ 
$\mathrm{kN} / \mathrm{mm}$, and $0.85 \pm 0.1 \mathrm{kN} / \mathrm{mm}$, respectively. Evident is that the stiffness of PPLGFY and PPSCGF is $57 \%$ and $74 \%$ lower than PPLGF. The plate mechanical behavior in the stable fracture under axial compression loading followed a predictable trend. No significant difference was found between the stiffness of the fixation plate structures in the unstable bone fracture. However, alternative fixation methods such as parallel plate construction or changing screws position might be better options for unstable bone fracture. Generally, the presented axial stiffness (in both stable and unstable bone fracture) of the proposed GF/PP composites are within the reported range in previous studies of metallic [30-32] and composite [33, 34] fixation plates.

PPLGF fixation plate structure has the highest axial stiffness in both types of bone fractures. The degradation of the fixation plate mechanical properties causes the overall stiffness reduction in the fracture fixation structure. PPSCGF has lower flexural stiffness, modulus, and strength values, making it less stiff than other composite plates. Generally, based on the achievements (see table 1), the highest reported flexural modulus value is still below the flexural modulus of the cortical bone (12-17 GPa [35]). This means that these plates can provide better behavior in bending than metallic plates, although they have provided the desired stiffness in compression for the initial healing phase to stabilize the fracture site concurrently. In addition, they cause the interfragmentary strain of about 2 to $10 \%$ in the second phase of healing (indirect healing) at the callus zone, which can promote the healing process. Hence, PPLGF and PPLGFY could be used in fracture fixation plates, which would reduce the stress shielding effect and allow required micro interfragmentary movement for callus formation. Furthermore, they can provide adequate initial fixation immediately after surgery, and they are capable of absorbing high energy vibration, which is occurred between the plate and fractured bone when the patient is walking. 
Besides, neat PP has changed behavior due to its utterly plastic behavior and densification. It has low stiffness in an unstable bone fracture, which leads the plate not to have the properties necessary for an orthopedic plate, but it can be used in hybrid composite fixation plate systems such as elastic screw holes fixation [7]. The hybrid composite fixation plate system reduces the induced primary shock of impact load, and by concentrating the stress at the screw-bone and screw-plate interfaces, it prevents structural damage of bone and fixation plate.

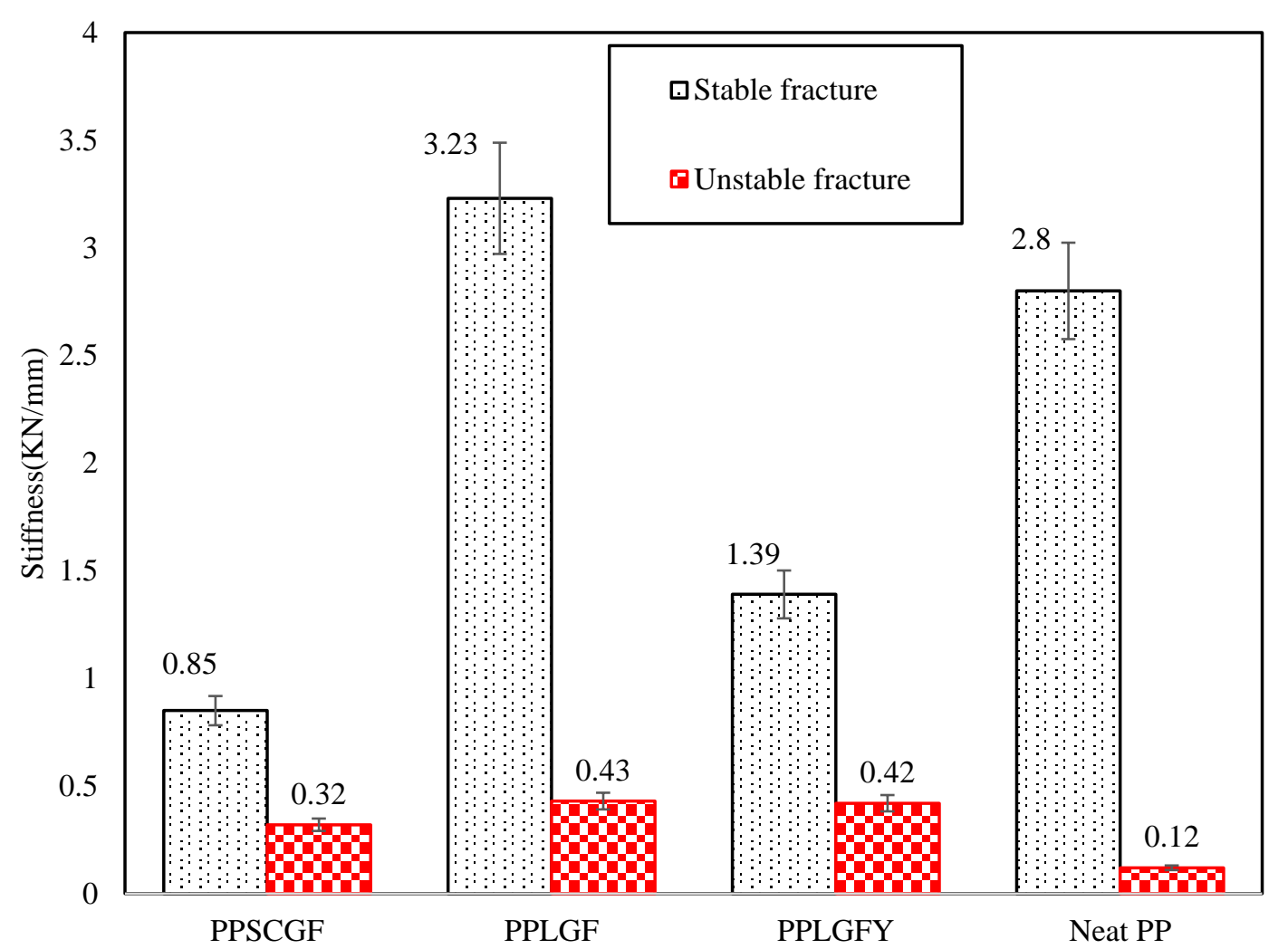

Figure 15. Comparison of fixation plate structures overall stiffness in stable and unstable bone fractures.

Patients often use crutches after surgery; thus, during the fracture healing, one-tenth of body weight is imposed by muscles at the end of the tibia for $1-8$ weeks of post-surgery. The load increases up to twice of body weight after week 8 until week 12. After that, the body weight increases gradually every week and reaches up to the bodyweight treble in 16 weeks after the surgery [36]. According to the results shown in figure 16, all three PP/Glass composite fixation 
plates can bear almost twice of body weight of an average weight person $(70 \mathrm{~kg})$ during fracture healing. Therefore, the proposed composite fixation plates can be recommended as proper candidates for orthopedic applications. There will, however, need to conduct some additional in vitro and in vivo studies with larger sample sizes to reach definitive conclusions.

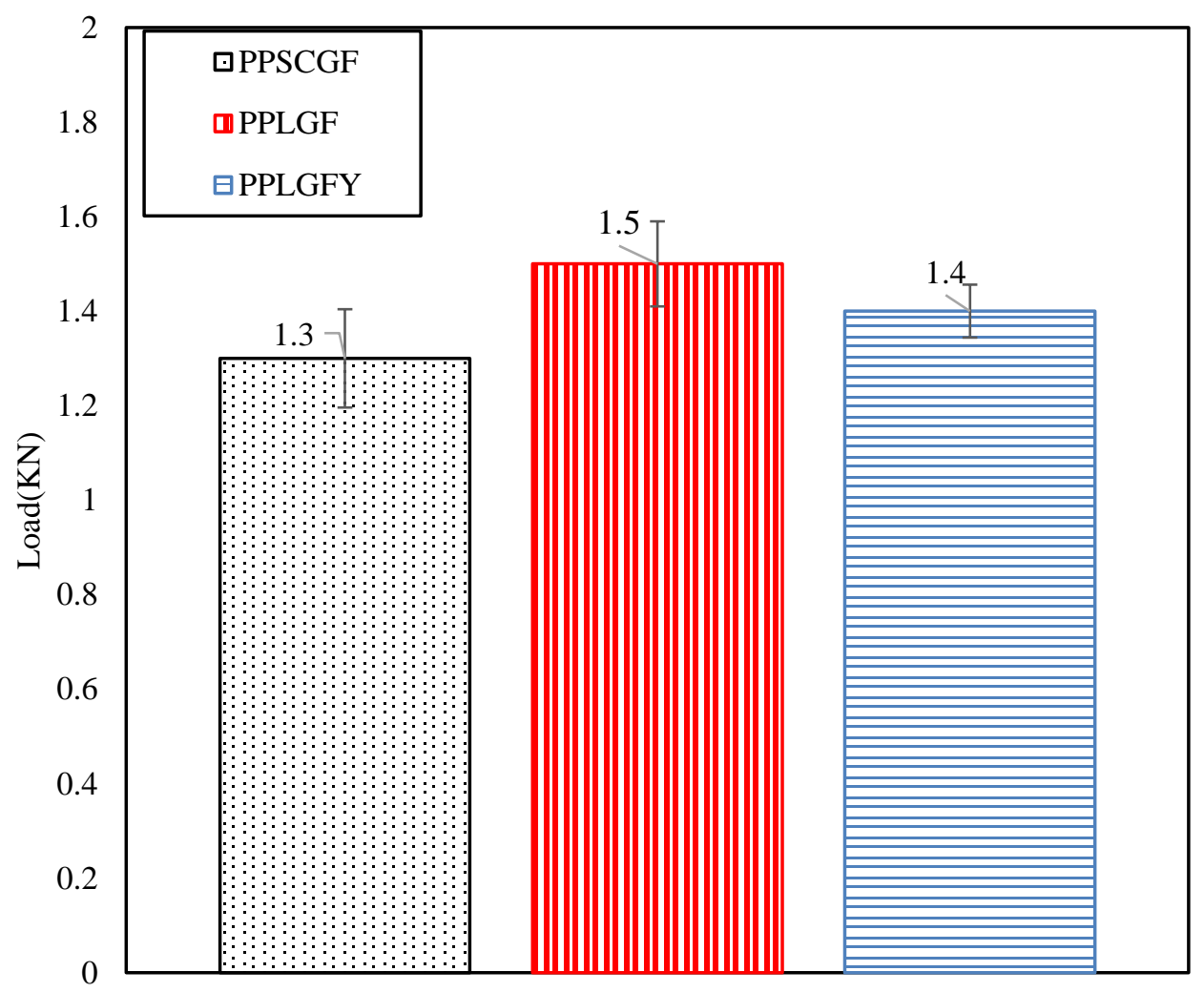

Figure 16. Comparison of composite fixation plate structures failure load in unstable bone fracture.

\subsection{Strain pattern of fixation plate systems}

In the case of low impact velocity, damage or breakage of the structural components in the early stages of the applied impact load does not occur, and the wave of compressive strain emerges in the fixation plate system. This wave in the fixation plate structures with a $1 \mathrm{~mm}$ fracture gap and $70 \mathrm{~J}$ impact energy is visible in figure 8 . This wave is neutralized before the global bending and shear strain waves move to the fixation plate structures sideways. 
Therefore, there are two stages during the striking of the fixation plate structures: propagation of longitudinal strain wave and the structure and propagation of transverse strain wave.

It is illustrated in figure 8 that the strain on the screws and plate increases during dynamic loading. Due to plastic behavior, impact energy absorption, and high Poisson's ratio of the neat PP, the pure plastic fixation plate showed a higher level of strain in the stable bone fracture. This fixation plate system absorbed the impact strains, which, in turn, less damage occurred in the bone. However, the focus of this study is on the comparison of three composite plates behavior. At the first stage, they endured compression load and raised localized plastic strain in the screws-plate interface. Then, the crack growing and the fixation plate system failure happened in the screws-plate interface. The final fracture pattern combines progressive compression, bending, and shear strains that causes yield strain at the screws-plate interface. The results confirm that the elastic-plastic behavior and toughness of materials play significant roles in the impact resistance of fixation plate systems.

Due to the plastic behavior and Young's modulus of the plates, the amount of created strains can be justified differently. In other words, the plates with the higher modulus (PPLGF and PPLGFY) have a lower strain for the PPSCGF plate (Figure 9). In addition, the orthotropic materials (PPLGF and PPLGFY) show more irregular strain wave behavior than isotropic material (PPSCGF). Due to the lower stiffness and invariant mechanical behavior through different directions, the strain behavior of PPSCGF was more stable than the other two materials. It can be concluded that less strain occurred during impact loading on a plate with a higher modulus and lower Poisson's ratio (Figure 9).

In general, a fixation plate that can reduce the level of transmitted peak force to bone or bone strain concentration in the screws-bone interface during impact loading would be recommended as a choice in orthopedic fixation plate applications. It should be noted that this 
reduction can be provided by absorbing plastic energy (neat PP) or by absorbing fracture energy (PPLGF, PPLGFY, and PPSCGF)).

\subsection{Stress analysis of fixation plate structures}

Generally, the stress on the plate was higher in the unstable situation compared to the stable fixation. Due to bending and compression of the plates during impact loading, the maximum Von-Mises stress was found in the fracture site's vicinity at the middle segment of the plates. However, the next highest stress in the plates was around the inner screw holes. The crack growing and the failure of the fixation plate system happened in the screws-plate interface. The maximum Von-Mises stress of PPSCGF was lower than the one induced in PPLGF and PPLGFY fixation plates (Figures 10-12). Due to the higher flexural modulus of the PPLGF, high stress occurred in its critical area. Since PPLGFY and PPSCGF have almost the same flexural modulus but different behavior, bending behavior is not the only reason for the stress distribution in the fixation plates. The difference of the tensile modulus and Poisson's coefficient of the materials also can be the reason for stress distribution changes. The behavior of neat PP was utterly different from the other three plates due to its plastic behavior. In other words, due to the plastic behavior, the middle segment of the plates was plasticized in the bending, and its Von-Mises stress changes were reduced.

Von-Mises mean stress was selected to be a parameter to assess the stress pattern changes. Mean stresses were smaller than the maximal stresses. Moreover, the bone stress was inversely proportional to the plate stress. The mean stress on the fractured bone, plate, and screws for all composite plates rapidly increased as the increase of impact energy level in both the fracture gap sizes of 1 and $5 \mathrm{~mm}$. However, due to plate failure in the fracture gap of $10 \mathrm{~mm}$, the mean stress decreased by increasing the impact energy level for all composite plates (Tables 5-7). Bone needs adequate stress to continue growing and healing, but enough amount will be the challenging question. The stress-induced in the bone with PPSCGF fixation plate was higher 
than the one with PPLGF and PPLGFY fixation plates (Tables 5-7). The highest Von-Mises stress level was especially located in the fractured bone surrounding the screw holes and beyond the ultimate compressive of cortical and trabecular bovine bone in high strain rate (250$400 \mathrm{MPa})[23,24]$. Since the mass loss due to bone resorption in bone with PPSCGF plate is reduced compared to the bone with PPLGF and PPLGFY plates, it shows higher density. This is due to the higher rate of bone regeneration and remodeling during the healing process under high-stress conditions, as per Wolf's law [2]. It has been observed that the fixation plate with low-stiffness material offers less stress-shielding to the bone and provides higher stress to induce accelerated healing. These results demonstrate that higher stress can be induced in the bone, incredibly close to the fractured region where a higher rate of bone remodeling is desired by adopting the proposed composite plates.

The stress analysis showed the screws almost presented a higher stress magnitude than the bone and plate, which was evident as the metallic screws had more Young's modulus (Table 5-7). The screws are in direct contact with the bone, which allow the direct load transfer from the plate to the bone. The mean stress at the screw head may reach $341 \mathrm{MPa}$ due to contact with its corresponding hole (Table 7). The closest screws to the stress concentrated areas on the plate experienced a higher amount of stress. In all materials considered in this study, the highest stress concentration occurred at the screw neck. In neat PP, since the plate did not break and deformed plastically, more stress was applied to the screws than the composite plates.

\subsection{Failure modes of fixation plate structures}

The amount of damage and failure modes depends on the plate mechanical strength (compressive, tensile, and shear strength). Moreover, the selected failure criterion (the principal maximum stress) plays an essential role in the numerical failure prediction. With the spread of the destruction mode, the material elements are damaged in all directions, and there is no capacity to bear the load. The same failure modes were obtained from numerical and 
experimental procedures, confirming that the principal maximum stress criterion has been able to predict the damage modes of the fixation plate systems.

In the stable fracture, local plastic deformation and crack growth in PPSCGF (Figure 13-a) and matrix cracking and fiber tearing in PPLGF, and PPLGFY fixation plate systems (Figures 13b and 13-c) occurred along the screw holes.

In the unstable bone fracture, the failure modes were caused by intense compression, and shear stresses beneath the screw holes, where the stress was concentrated. In PPSCGF, crack initiation occurred at the closest screw holes to the fracture site on the proximal tibia fragment, and finally, catastrophic fracture happened in a brittle manner. Longitudinal fractures beneath the screw holes were the main failure modes of PPSCGF (Figure 14-a). During the failure of PPLGF and PPLGFY fixation plate systems, matrix cracking, fiber tearing, and edge delaminating or long splitting in their glass fibers occurred. The cracks grow beneath the screw holes near the bone distal end and near the failed area in the entry point of the proximal screw holes (Figures 14-b and 14-c). Due to fiber interlayer damage and matrix crack growing, the deterioration trigger mechanism was the major fracture mechanism in PPLGFY and PPLGF fixation plate systems, and ultimate fracture occurred in the form of fiber breakage (Figures 14-b and 14-c).

It should be noted that the neat PP fixation plate system with low rigidity and entirely plastic behavior did not fail after applying impact force, and in both bone fracture types, plastic deformation occurred.

\section{Conclusion}

GF/PP composite fixation plates with three different glass fibers were fabricated by heatcompressing and 3D printing processes to address the metallic biomaterial drawbacks. The mechanical properties, as well as impact behavior of samples, were studied experimentally and 
numerically. A significant agreement between experimental and computational models was demonstrated. The parameters such as impact damping behavior, damage mechanisms, and stress and strain pattern of the different fixation plate systems in stable and unstable bone fractures at different impact energies were determined. The impact load-time responses and the failure mechanisms revealed that fixation plate systems with more plastic behavior and lower stiffness could act as initial shock absorbers and dampen the transmission of axial impact load by distributing the impact energy over time. Since all three composite fixation plate systems have a close mechanical property to the bone and their transmitted peak forces and impact durations are close to each other, they can replace traditional metallic plates for bone fractures. Based on static and quasi-static behavior, PPLGF and PPLGFY fixation plate systems are more appropriate for this purpose. Furthermore, the bone fracture incident would not occur during impact loading, which is one of the main advantages of composite plates over their metallic counterparts. Hence, to overcome the high failure rate of bone fractures and increase the resistance to loosening, such composites plates are proposed. However, to make a definite conclusion, additional in vitro and in vivo studies with larger sample sizes are needed.

\section{Conflict of interest statement}

None. 


\section{References}

[1] Chen Q, Thouas GA. Metallic implant biomaterials. Materials Science and Engineering: R: Reports. 2015; 87:1-57.

[2] Ramakrishna S, Mayer J, Wintermantel E, Leong KW. Biomedical applications of polymercomposite materials: a review. Composites science and technology. 2001; 61(9):1189-1224.

[3] Kim HJ, Kim SH, Chang SH. Finite element analysis using interfragmentary strain theory for the fracture healing process to which composite bone plates are applied. Composite structures. 2011; 93(11):2953-2962.

[4] Fouda N, Mostafa R, Saker A. Numerical study of stress shielding reduction at fractured bone using metallic and composite bone-plate models. Ain Shams Engineering Journal. 2019; 10(3):481-488.

[5] Mehboob H, Chang SH. Application of composites to orthopedic prostheses for effective bone healing: A review. Composite Structures. 2014; 118:328-341.

[6] Coates C, Goeser P, Coates-Clark C, Jenkins M. Impact Response and Simulation of Damaged Ulna With Internal Fixation. Journal of applied biomechanics. 2012; 28(3):324-334. [7] Capanni F, Hansen K, Fitzpatrick DC, Madey SM, Bottlang M. Elastically suspending the screw holes of a locked osteosynthesis plate can dampen impact loads. Journal of applied biomechanics. 2015; 31(3):164-169.

[8] Park SW, Yoo SH, An ST, Chang SH. Material characterization of glass/polypropylene composite bone plates according to the forming condition and performance evaluation under a simulated human body environment. Composites Part B: Engineering. 2012; 43(3):1101-1108. [9] Hertel R, Eijer H, Meisser A, Hauke C, Perren SM. Biomechanical and biological considerations relating to the clinical use of the Point Contact-Fixator--evaluation of the device handling test in the treatment of diaphyseal fractures of the radius and/or ulna. Injury. 2001; 32:B10-4.

[10] Kabiri A, Liaghat G, Alavi F, Saidpour H, Hedayati SK, Ansari M, Chizari M. Glass fiber/polypropylene composites with potential of bone fracture fixation plates: Manufacturing process and mechanical characterization. Journal of Composite Materials. 2020; 54(30):49034919.

[11] Sutradhar A, Park J, Carrau D, Miller MJ. Experimental validation of 3D printed patientspecific implants using digital image correlation and finite element analysis. Computers in biology and medicine. 2014; 52:8-17. 
[12] Chakraborty A, Datta P, Majumder S, Mondal SC, Roychowdhury A. Finite element and experimental analysis to select patient's bone condition specific porous dental implant, fabricated using additive manufacturing. Computers in Biology and Medicine. 2020:103839. [13] Hedayati SK, Behravesh AH, Hasannia S, Saed AB, Akhoundi B. 3D printed PCL scaffold reinforced with continuous biodegradable fiber yarn: A study on mechanical and cell viability properties. Polymer Testing. 2020; 83:106347.

[14] Zdero R, editor. Experimental methods in orthopaedic biomechanics. Academic Press; 2016.

[15] Ahmad M, Nanda R, Bajwa AS, Candal-Couto J, Green S, Hui AC. Biomechanical testing of the locking compression plate: when does the distance between bone and implant significantly reduce construct stability?. Injury. 2007; 38(3):358-364.

[16] Schreier H, Orteu JJ, Sutton MA. Image correlation for shape, motion and deformation measurements: Basic concepts, theory and applications. Boston, MA: Springer-Verlag US; 2009.

[17] Taherzadeh-Fard A, Liaghat G, Ahmadi H, Razmkhah O, Charandabi SC, Zarezadehmehrizi MA, Khodadadi A. Experimental and numerical investigation of the impact response of elastomer layered fiber metal laminates (EFMLs). Composite Structures. 2020:112264.

[18] Bayat A, Liaghat G, Sabouri H, Ashkezari GD, Pedram E, Taghizadeh SA, Khan MK, Razmkhah O. Experimental investigation on the quasi-static mechanical behavior of autoclaved aerated concrete insulated sandwich panels. Journal of Sandwich Structures \& Materials. 2019:1099636219857633.

[19] Ahmadi H, Rahimi G. Analytical and experimental investigation of transverse loading on grid stiffened composite panels. Composites Part B: Engineering. 2019; 159:184-198.

[20] Huiskes R, Chao EY. A survey of finite element analysis in orthopedic biomechanics: the first decade. Journal of biomechanics. 1983; 16(6):385-409.

[21] Schoßig M, Bierögel C, Grellmann W, Mecklenburg T. Mechanical behavior of glassfiber reinforced thermoplastic materials under high strain rates. Polymer Testing. 2008; 27(7):893-900.

[22] Kharazi AZ, Fathi MH. Load capacity assessment of a braided textile composite bone plate under real-life condition. International Journal of Biomedical Engineering and Technology. 2015; 18(2):186-198. 
[23] Yu B, Zhao GF, Lim JI, Lee YK. Compressive mechanical properties of bovine cortical bone under varied loading rates. Proceedings of the institution of mechanical engineers, Part H: Journal of engineering in medicine. 2011; 225(10):941-947.

[24] Szabó ME, Taylor M, Thurner PJ. Mechanical properties of single bovine trabeculae are unaffected by strain rate. Journal of biomechanics. 2011; 44(5):962-967.

[25] Haase K, Rouhi G. Prediction of stress shielding around an orthopedic screw: Using stress and strain energy density as mechanical stimuli. Computers in Biology and Medicine. 2013; 43(11):1748-1757.

[26] Quenneville CE, Dunning CE. Development of a finite element model of the tibia for short-duration high-force axial impact loading. Computer Methods in Biomechanics and Biomedical Engineering. 2011; 14(02):205-212.

[27] Milgrom C, Finestone A, Simkin A, Ekenman I, Mendelson S, Millgram M, Nyska M, Larsson E, Burr D. In vivo strain measurements to evaluate the strengthening potential of exercises on the tibial bone. The Journal of bone and joint surgery. British volume. 2000; 82(4):591-594.

[28] Burr DB, Milgrom C, Fyhrie D, Forwood M, Nyska M, Finestone A, Hoshaw S, Saiag E, Simkin A. In vivo measurement of human tibial strains during vigorous activity. Bone. 1996; 18(5):405-410.

[29] Augat P, Burger J, Schorlemmer S, Henke T, Peraus M, Claes L. Shear movement at the fracture site delays healing in a diaphyseal fracture model. Journal of orthopaedic research. 2003; 21(6):1011-1017.

[30] Bottlang M, Doornink J, Fitzpatrick DC, Madey SM. Far cortical locking can reduce stiffness of locked plating constructs while retaining construct strength. The Journal of Bone and Joint Surgery. American volume. 2009; 91(8):1985.

[31] Tsai S, Fitzpatrick DC, Madey SM, Bottlang M. Dynamic locking plates provide symmetric axial dynamization to stimulate fracture healing. Journal of Orthopaedic Research. $2015 ; 33(8): 1218-1225$.

[32] Moazen M, Leonidou A, Pagkalos J, Marghoub A, Fagan MJ, Tsiridis E. Application of far cortical locking technology in periprosthetic femoral fracture fixation: a biomechanical study. The Journal of arthroplasty. 2016; 31(8):1849-1856.

[33] Bagheri ZS, Tavakkoli Avval P, Bougherara H, Aziz MS, Schemitsch EH, Zdero R. Biomechanical analysis of a new carbon fiber/flax/epoxy bone fracture plate shows less stress 
shielding compared to a standard clinical metal plate. Journal of biomechanical engineering. 2014; 136(9).

[34] Siddiqui FS, Shah S, Nicayenzi B, Schemitsch EH, Zdero R, Bougherara H. Biomechanical analysis using infrared thermography of a traditional metal plate versus a carbon fibre/epoxy plate for Vancouver B1 femur fractures. Proceedings of the Institution of Mechanical Engineers, Part H: Journal of Engineering in Medicine. 2014; 228(1):107-113.

[35] Simkin A, Robin G. The mechanical testing of bone in bending. Journal of biomechanics. 1973; 6(1):31-39.

[36] Kim HJ, Chang SH, Jung HJ. The simulation of tissue differentiation at a fracture gap using a mechano-regulation theory dealing with deviatoric strains in the presence of a composite bone plate. Composites Part B: Engineering. 2012; 43(3):978-987. 